
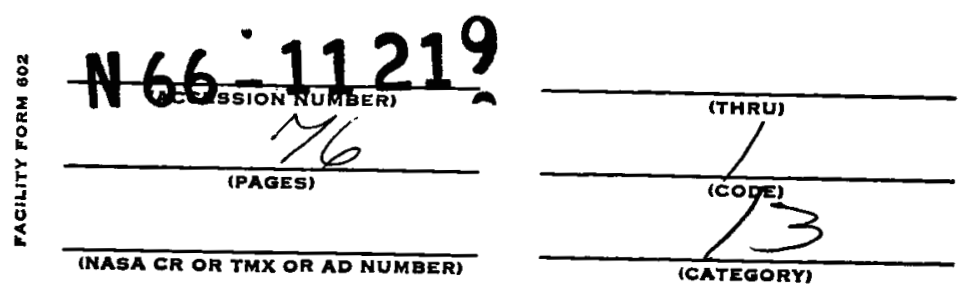

WASA TIM 55324

\title{
SOME GEOLOGICAL IMPLICATIONS OF EQUILIBRIUM BETWEEN GRAPHITE AND A C-H-O GAS PHASE AT HIGH TEMPERATURES AND PRESSURES
}

GPO PRICE

$\$$

CFSTI PRICE(S) \$

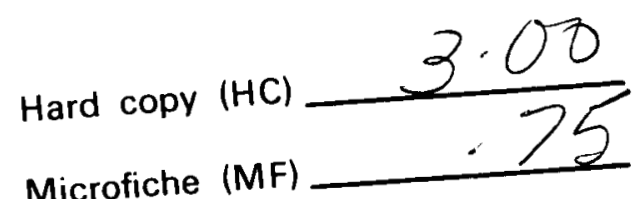


SOME GEOLOGIGAL IMPLIGATIONS OF EQUILIBRIUM

BETWEEN GRAPHITE AND A C-H-O GAS PHASE

AT HIGH TEMPERATURES AND PRESSURES

Bevan M. French

Theoretical Division Goddard Space Flight Center National Aeronautics and

Space Administration

Greenbelt, Maryland 


\section{ABSTRACT}

The occurrence of graphite as a common accessory mineral in meteorites and in terrestrial metamorphic and igneous rocks gives particular importance to the study of equilibrium between graphite and a coexisting gas phase. Using a simplified model in which $\mathrm{T}, \mathrm{P}_{\text {gas }}$, and $\mathrm{f}_{\mathrm{O}_{2}}$ are independently specified for the system $\mathrm{C}-\mathrm{H}-\mathrm{O}$, values of $\mathrm{P}_{\mathrm{CO}_{2}}, \mathrm{P}_{\mathrm{OO}}, \mathrm{P}_{\mathrm{H}_{2} \mathrm{O}}, \mathrm{P}_{\mathrm{H}_{2}}$, and $\mathrm{P}_{\mathrm{CH}_{4}}$ in a gas phase in equilibrium with graphite have been calculated for a wide range of geologically possible conditions by use of a high-speed computer. The numerical results support the following general conclusions: (1) The assumption that $\mathrm{P}_{\text {gas }}=\mathrm{P}_{\mathrm{H}_{2} \mathrm{O}}+\mathrm{P}_{\mathrm{CO}_{2}}$ is significantly in error for many graphite-bearing mineral assemblages. (2) Methane, $\mathrm{CH}_{4}$, may be a significant to dominant constituent of the gas phase in many possible geological environments involving moderate reduction; in particular, the occurrence of graphite with reduced minerals such as fayalite, wistite, and iron is indicative of a methane-rich gas phase. (3) Under metamorphic conditions, pure water is not stable with graphite; but graphite can coexist with a gas phase rich in $\mathrm{CO}_{2} \cdot$ (4) Original graphite in a sediment will stabilize increasingly reduced mineral assemblages during progressive thermal metamorphism. (5) The presence or absence of even small amounts of graphite can explain $\mathrm{P}_{\mathrm{O}_{2}}$ gradients observed over short distances or between adjacent layers in metamorphic rocks. (6) It is possible that the terrestrial atmosphere could have evolved by conversion of original methane to water and $\infty_{2}$ by reaction with graphite and other accessory minerals within the primordial earth at temperatures of $600^{\circ}$ to $1000^{\circ} \mathrm{C}$. Material requirements for such conversion are not unreasonable, and the process itself is consistent with many proposed models for the origin of the earth. 


\section{CONTENTS}

Symbols

Abbreviations for solid phases

Abbreviations for solid-phase buffer assemblages

INTRODUCTION

THEORETICAL CONSTRAINTS ON THE EQUILIBRIUM GALCULATIONS

Equilibrium between graphite and gas

Consideration of inorganic compounds only

Ideal behavior of the gas phase

GALCULATIONS OF EQUILIBRIUM BETWEEN GRAPHITE AND GAS

NUMERIGAL RESULTS AND SOME GEOLOGICAL IMPLICATIONS

Composition of the gas phase as a function of $\mathrm{f}_{\mathrm{O}_{2}}$

Significance of methane in equilibrium with graphite

Maximum $\mathrm{P}_{\text {gas }}$-temperature curves for graphite-bearing assemblages

Progressive metamorphism of graphite-bearing sediments

Mineral assemblages in meteorites

A POSSIBLE MECHANISM FOR EVOLUTION OF THE TERRESTRIAL ATMOSPHERE

GENERAL CONCLUSIONS

Acknowledgements

References 
Symbols

$\mathrm{T}$

Pas

$\mathbf{P}_{\mathbf{i}}$

$\mathrm{f}_{\mathrm{i}}$

$\gamma_{i}$

$\mathrm{K}_{\mathrm{i}}$

$\log \mathrm{N}$ Logarithm of $\mathrm{N}$ to the base 10 .

In $\mathrm{N}$ Logarithm of $\mathrm{N}$ to the base $\underline{\mathrm{e}}$.

Temperature in degrees Kelvin.

Total pressure of a gas phase.

$$
\mathrm{\gamma}_{\mathrm{i}}=\mathrm{f}_{\mathrm{i}} / \mathrm{P}_{\mathrm{i}}
$$
components.

P.

i

i

components.
$\log \mathrm{N}$ Logarithm of $\mathrm{N}$ to the base 10 .
ln $\mathrm{N} \quad$ Logarithm of $\mathrm{N}$ to the base $\underline{\mathrm{e}}$.

Partial pressure of component $\underline{i}$ in the gas phase.

Fugacity of component $\underline{i}$ in the gas phase.

Fugacity coefficient of component $\underline{i}$ in the gas phase, defined by

Equilibrium constant of the $\underline{i}$ th reaction, defined by $\Delta G^{\circ}=-R T$ In $K_{i}$.

A function of $T$ only when written using fugacities of volatile 


\section{Abbreviations for solid phases}

\begin{tabular}{|c|c|c|}
\hline $\mathrm{H}$ & hematite & $\mathrm{Fe}_{2} \mathrm{O}_{3}$ \\
\hline M & magnetite & $\mathrm{Fe}_{3} \mathrm{O}_{4}$ \\
\hline W & wistite & $\mathrm{Fe}_{1-\mathrm{x}^{\mathrm{O}}}$ \\
\hline I & iron & $\mathrm{Fe}$ \\
\hline $\mathrm{N}$ & nickel & $\mathrm{Ni}$ \\
\hline NO & $\begin{array}{l}\text { nicke1 oxide } \\
\text { (bunsenite) }\end{array}$ & $\mathrm{NiO}$ \\
\hline$Q$ & quartz & $\mathrm{SiO}_{2}$ \\
\hline$F$ & fayalite & $\mathrm{Fe}_{2} \mathrm{SiO}_{4}$ \\
\hline $\mathrm{Gr}$ & graphite & $\mathrm{C}$ \\
\hline
\end{tabular}

Abbreviations for solid-phase oxygen buffer assemblages (Eugster and Wones, (1962).

HM hematite + magnetite

NNO nickel + bunsenite

MW magnetite + wistite

QFM quartz + fayalite + magnetite

WI wllstite + iron

QFI quartz + fayalite + iron

MI magnetite + iron 


\section{INTRODUCTION}

The system $\mathrm{C}-\mathrm{H}-\mathrm{O}$ is of extreme importance in consideration of any fundamental problems concerning the origin and development of the earth and the solar system. Part of the importance is due to the fact that the three elements together comprise about 63 per cent by weight of the matter in the universe (Allen, 1963, p. 30-33), of which almost all is hydrogen. If the inert gases helium and argon are excluded, then carbon, hydrogen, and oxygen make up about 99 per cent. In addition, the system contains such biologically important compounds as water, oxygen, and carbon dioxide, which are of prime importance in speculations about the origin of the terrestrial oceans and atmosphere and the origin of life. Calculations of equilibrium in the system $\mathrm{C}-\mathrm{H}-\mathrm{O}$ are complicated by the large number of organic and inorganic compounds which the system contains; high-speed computers have recently been employed to solve the numerous equilibria involved. In previous studies, the elemental composition of the system has been arbitrarily specified in order to supply sufficient constraints for solution of the equations applied to a single ideal fluid phase. Suess (1962) has presented calculations involving only the compounds $\mathrm{H}_{2} \mathrm{O}, \mathrm{H}_{2}, \mathrm{CO}_{2}, \infty$, and $\mathrm{CH}_{4}$, calculating partial pressures as functions of the composition of the system. A more general calculation involving additional elemental components (Dayhoff et al., 1964) produced additional equilibrium concentrations for a number of organic compounds of biological importance.

Such calculations, in which total composition of the system is initially specified, yield considerable information, but the data are not directly applicable to a number of important geological problems. In geological 
processes such as the metamorphism of sediments, it is not generally possible to specify the total composition of the system or to assume that the composition has remained constant. Commonly, the composition of the system will change during such processes by gain or loss of both volatile and involatile components. Thus, the chemical potentials of the components become more important than the original compositions in defining the behavior of the system at any given time (Thompson, 1955; Korzhinskii, 1959; Zen, 1963).

Further, in geological investigations, it is generally impossible to obtain a sample of the original fluid phase. One is thus compelled to study the compositions of the solid minerals in order to estimate the nature of the fluid phase with which they were equilibrated.

The present study considers equilibrium between graphite and a gas phase in the system $\mathrm{C}-\mathrm{H}-\mathrm{O}$ over a range of geologically reasonable temperatures and gas pressures. It is an extension of work carried out on the system C-O (French and Eugster, 1965), which considered the effect of graphite on $\mathrm{P}_{\mathrm{O}_{2}}$ in geological assemblages. The present study consists of three stages. First, compositions of the gas phase in equilibrium with graphite are calculated by use of a high-speed computer. Second, independent estimation of $\mathrm{P}_{2}$ for assemblages of iron-bearing minerals is applied to the data to estimate the composition of the coexisting gas phase. Finally, the data are applied to a simplified model in order to suggest a possible method for evolution of the terrestrial atmosphere. 
THEORETICAL CONSTRAINTS ON THE EQUILIBRIUM CALCULATIONS

The calculations described here have been obtained from a model which incorporates the following assumptions: (1) that continuous equilibrium is established between crystalline graphite and a gas phase whose composition lies in the system $\mathrm{C}-\mathrm{H}-\mathrm{O}$; (2) that the significant species in the gas phase are $\mathrm{C}_{2}, \infty, \mathrm{H}_{2} \mathrm{O}, \mathrm{H}_{2}, \mathrm{CH}_{4}$, and $\mathrm{O}_{2}$; equilibria involving more complex organic compounds are not considered; (3) that the gas phase exhibits ideal behavior under all conditions. The implications of these assumptions are discussed in turn.

Equilibrium between graphite and gas.

In the ternary system $\mathrm{C}-\mathrm{H}-\mathrm{O}$, under suitably reducing conditions, solid carbon (graphite at low pressures) can form over a wide range of temperatures and gas pressures. The presence of graphite in the assemblage reduces the number of variables which must be specified to fix the composition of the gas phase. The two-phase assemblage, graphite + gas, may be shown by the Gibbs Phase Rule to be trivariant, since $F=C-P+2=3$ (French and Eugster, 1965, P. 1537).

Graphite, or amorphous carbonaceous material, is a common trace constituent of numerous sediments and metamorphic rocks and has occasionally been observed in terrestrial igneous rocks and in meteorites. The effects of such material on controlling $\mathrm{P}_{\mathrm{O}_{2}}$ have been previously suggested (Miyashiro, 1964; Mueller, 1964; French, 1964). The assumption that graphite is present in natural assemblages is therefore reasonable. The calculations discussed are strictly applicable only to crystalline graphite and not to amorphous organic material which may originally be present in sediments and low-grade 
metamorphic rocks. However, such material is observed to change to graphite with increasing metamorphism (Quinn and Glass, 1958; French, 1964).

The model also requires continuous equilibration with a gas phase of the proper composition. It does not apply to systems in which a large part of the gas phase is composed of additional elements (e.g., N, S, or C1) or to systems which are so dry and impermeable that no gas phase can exist. Processes occuring only in the subsolidus, e.g., exsolution of graphite from an iron-carbon alloy, are likewise excluded from consideration. Consideration of inorganic compounds only

It is assumed here that the compounds $\infty_{2}, \infty, \mathrm{H}_{2} \mathrm{O}, \mathrm{H}_{2}, \mathrm{CH}_{4}$, and $\mathrm{O}_{2}$ constitute the total pressure of the gas phase, since these are the major volatile species involved in reactions between minerals. A detailed calculation of equilibrium compositions for a phase containing additional organic compounds (Dayhoff et al., 1964) provides support for this assumption by indicating, (1) that the compounds listed do compose almost the entire gas pressure, and (2) that the partial pressure of $\mathrm{CH}_{4}$ greatly exceeds that of the more complex organic compounds. It is therefore believed that no great discrepancy is introduced by this assumption.

Ideal Behavior of the Gas Phase

The assumption that the gas phase behaves ideally has been incorporated into earlier calculations involving the system C-H-O (Krauskopf, 1959; Suess, 1962; Holland, 1962; Dayhoff et al., 1964). This assumption probably introduces the largest uncertainty into the numerical results obtained in the present study. As discussed below, the effect of this assumption is difficult to estimate, but it is believed that the present resilts are 
satisfactory for semiquantitative considerations and that none of the general conclusions is invalidated.

There is presently little experimental data on the behavior of mixtures of the gas species at high pressures, but available data do indicate that the behavior will be nonideal at low temperatures. An immiscibility gap exists in the system $\mathrm{H}_{2} \mathrm{O}-\mathrm{CO}_{2}$ (Malinin, 1959; Todheide and Franck, 1963; Takenouchi and Kennedy, 1964); although there are slight differences between the experimental results, it appears that the two-phase region lies at temperatures below the critical point of water $\left(373^{\circ} \mathrm{C}\right)$ for values of $\mathrm{P}_{\text {gas }}$ less than $2000 \mathrm{~b}$. Below $400 \mathrm{~b}$. total gas pressure, the two-phase region apparently lies below $350^{\circ} \mathrm{C}$. The effect of other compounds on the location of the two-phase region is uncertain; large amounts of methane might move the critical surface to even low temperatures.

Preliminary experimental data (H. J. Greenwood, personal communication) indicate that the system $\mathrm{H}_{2} \mathrm{O}-\mathrm{OO}_{2}$ exhibits nearly ideal behavior at higher temperatures. Nevertheless, it seems clear that numerical results based on an ideal-gas model are only speculative below $300^{\circ} \mathrm{C}$; only the results given here for temperatures above $600^{\circ} \mathrm{K}\left(327^{\circ} \mathrm{C}\right)$ are considered as reasonable approximations to the actual behavior of the system.

Although there are no data available for fugacity coefficients of the various species in mixtures, values of $\gamma_{i}$ for individual species have been compiled as functions of temperature and pressure for $\mathrm{CO}_{2}$ (Kennedy, 1954; Robie, 1962), $\infty$ (Newton, 1935), $\mathrm{H}_{2} \mathrm{O}$ (Anderson, 1964), $\mathrm{H}_{2}$ (Shaw and Wones, 1964), and $\mathrm{CH}_{4}$ (Douslin et al., 1964). A closer approximation to the actual behavior of the gas phase could be made by assuming that values of $\gamma_{i}$ in the mixture are the same as for the pure species at the same temperature and 
pressure (Lewis and Randall's Rule; see Denbigh, 1957). Even this approximation may not be valid at extremely high pressures.

In view of the uncertainty in $\gamma_{i}$ for the gas species, it seems unwarranted to attempt to compensate for nonideal behavior in the present calculations.

An estimate of the uncertainty introduced by assuming ideal behavior is carried out below by performing parallel derivations for ideal and nonideal gas phases. 


\section{CALCULATIONS OF EQUILIBRIUM BETWEEN GRAPHITE AND GAS}

In a system which conforms to the assumption 1 isted, the various possible equilibria between graphite and the gas phase are specified by the equilibrium constants of the following four independent equations (French and Eugster, 1965, P. 1537):
(1) $\mathrm{C}+\mathrm{O}_{2}=\mathrm{CO}_{2}$
$\mathrm{K}_{1}=\frac{\mathrm{f}_{\mathrm{CO}_{2}}}{\mathrm{f}_{\mathrm{O}_{2}}}=\frac{\mathrm{\gamma}_{\mathrm{CO}_{2}}{ }^{\mathrm{P}} \mathrm{CO}_{2}}{\mathrm{\gamma}_{\mathrm{O}_{2}}{ }^{\mathrm{P}} \mathrm{O}_{2}}$
(2) $\mathrm{C}+1 / 2 \mathrm{O}_{2}=\infty$
$K_{2}=\frac{f_{\infty O}}{\left(f_{O_{2}}\right)^{\frac{1}{2}}}=\frac{\gamma_{\infty} P_{\infty}}{\left(\gamma_{O_{2}}{ }^{P_{O_{2}}}\right)^{\frac{1}{2}}}$
(3) $\mathrm{C}+2 \mathrm{H}_{2}=\mathrm{CH}_{4}$
$\mathrm{K}_{3}=\frac{\mathrm{f}_{\mathrm{CH}_{4}}}{\left(\mathrm{f}_{\mathrm{H}_{2}}\right)^{2}}=\frac{Y_{\mathrm{CH}_{4}} \mathrm{P}_{\mathrm{CH}_{4}}}{\left(\mathrm{Y}_{\mathrm{H}_{2}}{ }^{\mathrm{P}_{\mathrm{H}_{2}}}\right)^{2}}$
(4) $\mathrm{H}_{2}+1 / 2 \mathrm{O}_{2}=\mathrm{H}_{2} \mathrm{O}$

$$
K_{4}=\frac{f_{\mathrm{H}_{2} \mathrm{O}}}{\mathrm{f}_{\mathrm{H}_{2}}\left(\mathrm{f}_{\mathrm{O}_{2}}\right)^{\frac{1}{2}}}=\frac{\gamma_{\mathrm{H}_{2} \mathrm{O}} \mathrm{P}_{\mathrm{H}_{2} \mathrm{O}}}{\gamma_{\mathrm{H}_{2}} \mathrm{P}_{\mathrm{H}_{2}}\left(\mathrm{Y}_{\mathrm{O}_{2}} \mathrm{P}_{\mathrm{O}_{2}}\right)^{\frac{1}{2}}}
$$

Combining (1-4) with the condition that $P_{\text {gas }}$ must equal the sum of all $\mathrm{P}_{\mathrm{i}}$, we obtain five equations involving six variables, $\mathrm{P}_{\infty_{2}}, \mathrm{P}_{\infty}, \mathrm{P}_{\mathrm{H}_{2} \mathrm{O}}, \mathrm{P}_{\mathrm{H}_{2}}$, ${ }^{\mathrm{P}} \mathrm{CH}_{4}$, and $\mathrm{P}_{\mathrm{O}_{2}}$.

(1a) $\mathrm{P}_{\infty_{2}}=\frac{\mathrm{K}_{1} \psi_{\mathrm{O}_{2}}{ }^{\mathrm{P}_{\mathrm{O}_{2}}}}{{ }_{\mathrm{OO}_{2}}}=\frac{\mathrm{K}_{1}}{\gamma_{\mathrm{O}_{2}}} \mathbf{f}_{\mathrm{O}_{2}}$

(2a) $\mathbf{P}_{\infty}=\frac{\mathrm{K}_{2}\left(\mathrm{YO}_{2} \mathrm{P}_{\mathrm{O}_{2}}\right)^{\frac{1}{2}}}{\mathrm{Y}_{\infty}}=\frac{\mathrm{K}_{2}}{\mathrm{Y}_{C O}}\left(\mathrm{f}_{\mathrm{O}_{2}}\right)^{\frac{1}{2}}$ 


$$
\begin{aligned}
& \text { (3a) } \quad \mathrm{P}_{\mathrm{CH}_{4}}=\frac{\mathrm{K}_{3}\left(\gamma_{\mathrm{H}_{2}} \mathrm{P}_{\mathrm{H}_{2}}\right)^{2}}{\gamma_{\mathrm{CH}_{4}}}
\end{aligned}
$$

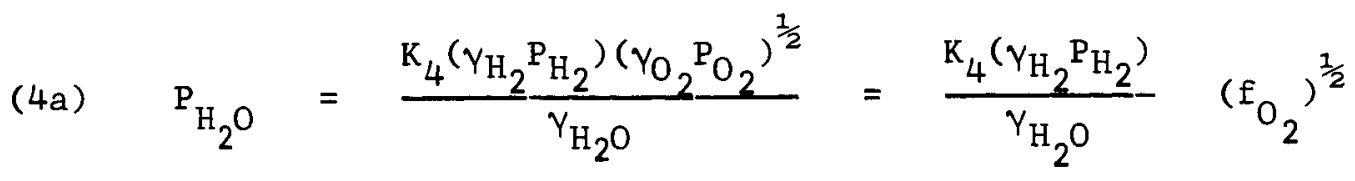

$$
\begin{aligned}
& \text { (5) } \quad \mathrm{P}_{\text {gas }}=\mathrm{P}_{\mathrm{O}_{2}}+\mathrm{P}_{\mathrm{CO}}+\mathrm{P}_{\mathrm{H}_{2} \mathrm{O}}+\mathrm{P}_{\mathrm{H}_{2}}+\mathrm{P}_{\mathrm{CH}_{4}}+\mathrm{P}_{\mathrm{O}_{2}}
\end{aligned}
$$

Thus, for any specified $T$ and $P_{\text {gas }}$, the values of any $f i v e P_{i}$ are explicitly determined if the sixth is independently specified. This result agrees with that of the Gibbs Phase Rule; the system graphite-gas is trivariant and becomes univariant if any two variables (e.g., temperature and total gas pressure) are specified.

Theoretically, one can specify any $\mathrm{P}_{i}$ for calculation of the others. In practice, in systems involving both natural minerals and synthetic phases, it is convenient to specify $\mathrm{P}_{\mathrm{O}_{2}}$ (or $\mathrm{f}_{\mathrm{O}_{2}}$ ) as the independent variable. Numerous mineral assemblages which contain iron- and manganesebearing phases are related by oxidation-reduction reactions which are conveniently written in terms of $\mathrm{P}_{\mathrm{O}_{2}}$. Changes in $\mathrm{P}_{\mathrm{O}_{2}}$ will be reflected by resultant changes in the mineral assemblage (Eugster, 1959; Eugster and Wones, 1962; Buddington and Lindsley, 1964). Conversely, it may be possible to deduce approximate values of $\mathrm{P}_{\mathrm{O}_{2}}$ from the mineral assemblage and thereby calculate partial pressures of other species.

The subsequent calculations are therefore carried out by specifying $\mathrm{T}, \mathrm{P}_{\text {gas }}$, and $\mathrm{f}_{\mathrm{O}_{2}}$ (specifying $\mathrm{f}_{\mathrm{O}_{2}}$ removes the necessity of considering $\mathrm{Y}_{2}$ in the equations). 
Equations ( $1 \mathrm{a}$ ) and (2a) demonstrate that values of $\mathrm{P}_{\mathrm{CO}_{2}}$ and $\mathrm{P}_{\mathrm{CO}}$ depend only on temperature and $\mathrm{f}_{\mathrm{O}_{2}}$ and are independent of $\mathrm{P}_{\text {gas }}$ (except for the slight effect of $\mathrm{P}_{\text {gas }}$ on $Y_{i}$ ). The values of $\mathrm{P}_{\mathrm{CO}_{2}}$ and $\mathrm{P}_{\mathrm{CO}}$ can thus be calculated directly and substituted in (5), as:

(5a)

$$
\mathrm{P}_{\mathrm{CH}_{4}}+\mathrm{P}_{\mathrm{H}_{2}}+\mathrm{P}_{\mathrm{H}_{2} \mathrm{O}}=\mathrm{P}_{\text {gas }}-\left(\mathrm{P}_{\mathrm{CO}_{2}}+\mathrm{P}_{\mathrm{CO}}+\mathrm{P}_{\mathrm{O}_{2}}\right)
$$

The value of $\mathrm{P}_{2}$ will be under $10^{-10} \mathrm{~b}$. in most geological assemblages, particularly if graphite is also present (Eugster, 1959; French and Eugster, 1965); the term can therefore be neglected.

The lefthand side of (5a) can be written in terms of $\mathrm{P}_{\mathrm{H}_{2}}$ and known quantities by substituting (3a) and (4a).

$$
\frac{\mathrm{K}_{3}\left(\gamma_{\mathrm{H}_{2}} \mathrm{P}_{\mathrm{H}_{2}}\right)^{2}}{\gamma_{\mathrm{CH}_{4}}}+\mathrm{P}_{\mathrm{H}_{2}}+\frac{\mathrm{K}_{4}\left(\gamma_{\mathrm{H}_{2}} \mathrm{P}_{\mathrm{H}_{2}}\right)}{\gamma_{\mathrm{H}_{2} \mathrm{O}}}\left(\mathrm{f}_{\mathrm{O}_{2}}\right)^{\frac{1}{2}}=\mathrm{P}_{\text {gas }}-\left(\mathrm{P}_{\infty}+\mathrm{P}_{\infty}\right)
$$

This expression is rearranged to obtain a quadratic equation in which $\mathrm{P}_{\mathrm{H}_{2}}$ is the only unknown.

$$
\left(\mathrm{P}_{\mathrm{H}_{2}}\right)^{2}\left[\frac{\mathrm{K}_{3} \mathrm{Y}_{\mathrm{H}_{2}}^{2}}{\gamma_{\mathrm{CH}_{4}}}\right]+\mathrm{P}_{\mathrm{H}_{2}}\left[\frac{\mathrm{K}_{4} \mathrm{Y}_{\mathrm{H}_{2}}\left(\mathrm{f}_{\mathrm{O}_{2}}\right)^{\frac{1}{2}}}{\mathrm{Y}_{\mathrm{H}_{2} \mathrm{O}}}+1\right]-\left[\mathrm{P}_{\text {gas }}-\left(\mathrm{P}_{\infty_{2}}+\mathrm{P}_{\infty}\right)\right]=0
$$

Solving, we obtain,

$$
\mathrm{P}_{\mathrm{H}_{2}}=\frac{-\left[\frac{\mathrm{K}_{4} \mathrm{\gamma}_{\mathrm{H}_{2}}\left(\mathrm{f}_{\mathrm{O}_{2}}\right)^{\frac{1}{2}}}{\mathrm{\gamma}_{\mathrm{H}_{2} \mathrm{O}} \mathrm{O}}+1\right]}{2\left[\frac{\mathrm{K}_{3} \mathrm{Y}_{\mathrm{H}_{2}}^{2}}{\mathrm{\gamma}_{\mathrm{CH}_{4}}}\right]}
$$




$$
+\frac{\left\{\left[\frac{\mathrm{K}_{4} \gamma_{\mathrm{H}_{2}}\left(\mathrm{f}_{\mathrm{O}_{2}}\right)^{\frac{1}{2}}}{\gamma_{\mathrm{H}_{2}} \mathrm{O}}+1\right]^{2}+4\left[\frac{\mathrm{K}_{3} \gamma_{\mathrm{H}_{2}}^{2}}{\gamma_{\mathrm{CH}_{4}}}\right]\left[\mathrm{P}_{\text {gas }}-\left(\mathrm{P}_{\mathrm{CO}_{2}}+\mathrm{P}_{\mathrm{CO}}\right)\right]\right\}^{\frac{1}{2}}}{2\left[\frac{\mathrm{K}_{3} \gamma_{\mathrm{H}_{2}}}{\gamma_{\mathrm{CH}_{4}}}\right]}
$$

Values of $\mathrm{P}_{\mathrm{H}_{2}}$ obtained from the positive root of (7) can then be substituted in ( $3 a$ ) and (4a) to derive, respectively, $\mathrm{P}_{\mathrm{CH}_{4}}$ and $\mathrm{P}_{\mathrm{H}_{2}} \mathrm{O}$. For: an. ideal gas, all $P_{i}=f_{i}$ and all $\gamma_{i}=1$. Under these conditions, (7) becomes:

$$
\begin{aligned}
& \mathrm{P}_{\mathrm{H}_{2}}=\frac{-\left[\mathrm{K}_{4}\left(\mathrm{f}_{\mathrm{O}_{2}}\right)^{\frac{1}{2}}+1\right]}{2 \mathrm{~K}_{3}} \\
& +\frac{\left\{\left[\mathrm{K}_{4}\left(\mathrm{f}_{\mathrm{O}_{2}}\right)^{\frac{1}{2}}+1\right]^{2}+4 \mathrm{~K}_{3}\left[\mathrm{P}_{\text {gas }}-\left(\mathrm{P}_{\mathrm{O}_{2}}+\mathrm{P}_{\infty}\right)\right]\right\}^{\frac{1}{2}}}{2 \mathrm{~K}_{3}}
\end{aligned}
$$

Comparison of (7) and (8) indicates that the difference between values of $\mathrm{P}_{\mathrm{H}_{2}}$ obtained by each method will probably be less than an order of magnitude. Available data on the fugacity coefficients of the pure species indicate that, above $500^{\circ} \mathrm{K}$, values of $Y_{i}$ lie within the range $0.7-3.0$. This variability will be reduced because the fugacity coefficients appear in (7) as ratios, and values of $\gamma_{i}$ will tend to be similar for the same temperature and pressure (Newton, 1935).

It is therefore believed that the errors introduced into the calculated $\mathbf{P}_{\mathbf{i}}$ by postulating an ideal gas phase will be less than an order of magnitude and probably closer to a factor of two. Such a discrepancy is not believed sufficient to change the general conclusions obtained and may be minimized 
by presenting results in terms of $\log P_{i}$. Further experimental work would be necessary to obtain more accurate values of $\gamma_{i}$ for refinement of the results. One possible refinement would involve using values of $Y_{i}$ for the pure species in accordance with Lewis and Randall's Rule, but the small anticipated correction does not seem to justify introduction of the additional complications into the present study.

Accordingly, calculations of $\mathrm{P}_{i}$ are carried out for an ideal gas, using values of $\mathrm{T}, \mathrm{P}_{\text {gas }}$, and $\mathrm{E}_{\mathrm{O}_{2}}$ selected to cover a wide range of possible geological environments. Calculations were carried out on an IBM $7090 / 7094$ system, using a program written in FORTRAN IV language by Mr. Arthur Smith of the Theoretical Division, NASA, Goddard Space Flight Center. The values of $k_{i}$ were obtained from JANAF Tables and did not differ significantly from those of earlier compilations (Wagman et al., 1945). The calculations covered a temperature range of $300^{\circ}$ to $1500^{\circ} \mathrm{K}$, a pressure range of 1 bar to 100 kilobars, and values of $\mathrm{f}_{\mathrm{O}_{2}}$ approximating the interval between the quartz-fayalite-iron and hematite-magnetite buffers (Eugster and Wones, 1962). The results presented in the text figures were checked by substituting the values of $P_{i}$ into $(1-5)$ to calculate $k_{i} \cdot 1$

\section{${ }^{1}$ Between $298^{\circ}$ and $1200^{\circ} \mathrm{K}$, graphite becomes metastable with respect to} diamond at pressures above about 16 to $40 \mathrm{~kb}$, respectively (Bundy et al., 1961). The transformation introduces a slight additional uncertainty into the numerical results obtained for values of $\mathrm{P}_{\text {gas }}$ above these 1 imits. No correction for this effect has been made, since the probable nonideality of the gas phase at such high pressures will introduce a greater error into 
the results than that caused by the slight difference in $\Delta G^{0}, 0.5$ to 1.7 $\mathrm{kcal} . / \mathrm{mole}$, involved in the diamond-graphite transformation. Furthermore, the following discussion is concerned almost exclusively with the region within which graphite is stable.

No correction has been made for the effect of pressure on the equilibrium constants of the heterogeneous reactions (1-3), in which the solid phase graphite participates. Because of the small molar volume of graphite, the change in $\log \mathrm{K}_{i}$ for these reactions with pressure is only $-0.028\left(\mathrm{P}_{\text {gas }^{-1}}\right) / \mathrm{T}$ (French and Eugster, 1965, P. 1534). For extreme conditions ( $P_{\text {gas }}=10 \mathrm{~kb} ., \mathrm{T}=600^{\circ} \mathrm{K}$ ), the change in $\log \mathrm{K}_{i}$ is less than -0.5 ; for pressures up to $2 \mathrm{~kb}$., the difference will be less than 0.1 , and the resultant uncertainties do not appear to exceed those introduced by the assumption of ideal behavior. 
NUMERICAL RESULTS AND SOME GEOLOGICAL IMPLICATIONS

Composition of the Gas Phase as a Function of $\underset{\mathrm{f}}{\mathrm{O}_{2}}$

The figures and discussion which follow represent only selected samples of the large amount of numerical data obtained through use of a high-speed computer. The choice is relatively arbitrary, but a selection has been made which is intended to apply chiefly to terrestrial geological processes under conditions for which the original assumptions remain reasonably valid.

Figures (1-3) present values of $\log \mathrm{P}_{\mathrm{i}}$ as a function of $\log \mathrm{f}_{\mathrm{O}_{2}}$

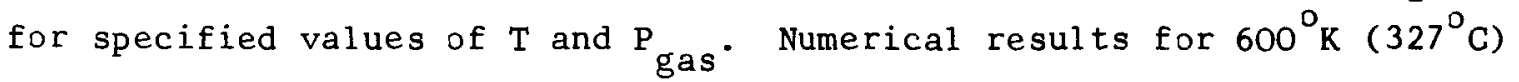
are shown in Figure 1 for total gas pressures of 1 bar, 1000 bars, and 10 kilobars. This temperature is reasonable for low-grade metamorphism (approximately the greenschist facies; Turner and Verhoogen, 1960, p. 534). The dotted portions of the curves correspond to values of $\log \mathrm{f}_{\mathrm{O}_{2}}$ for which the quantity $\left(\mathrm{P}_{\mathrm{CO}_{2}}+\mathrm{P}_{\mathrm{O}}\right)$ becomes greater than $\mathrm{P}_{\text {gas }}$, and for which solutions of (8) are not possible. Values of $\log \mathrm{f}_{\mathrm{O}_{2}}$ for various solid-phase oxygen buffer assemblages (Eugster and Wones, 1962) are indicated on the abscissa. Similar plots are presented for $900^{\circ} \mathrm{K}\left(627^{\circ} \mathrm{C}\right)$, a temperature which represents probable high-grade metamorphic conditions (Fig. 2) and for $1200^{\circ} \mathrm{K}\left(927^{\circ} \mathrm{C}\right)$, a reasonable estimate for pyrometamorphism or for some igneous phenomena (Fig. 3).

Several general conclusions appear from the figures. At constant $T$ and $\mathrm{f}_{\mathrm{O}_{2}}$, higher gas pressures favor a reduced gas phase richer in $\mathrm{CH}_{4}$ and $\mathrm{H}_{2}$. Conversely, for a given $\mathrm{P}_{\text {gas }}$ and $\mathrm{f}_{\mathrm{O}_{2}}$, increasing temperatures produce a gas phase which becomes more oxidized and $\mathrm{H}_{2} \mathrm{O}$ and $\mathrm{CO}_{2}$ appear at the expense of $\mathrm{CH}_{4}$. 
Throughout the temperature range considered, $\mathrm{H}_{2} \mathrm{O}$ exceeds $\mathrm{CO}_{2}$ in the gas, even though the gas phase may consist chiefly of other species.

Finally, for a wide range of geologically reasonable conditions, corresponding to the lower part of the stability field of magnetite, methane $\left(\mathrm{CH}_{4}\right)$ is a significant to dominant constituent of the gas phase, particularly at lower temperatures (bel ow $600^{\circ} \mathrm{C}$ ) and higher fluid pressures. This observation has particular significance for speculations about the fluid phase in equilibrium with low- to medium-grade metamorphic rocks and with ore minerals in certain hydrothermal deposits. The data presented indicate that, at $\mathrm{f}_{2}$ values suitable for the appearance of fayalite or wllstite, the gas phase is almost entirely methane, particularly below $500^{\circ} \mathrm{C}$. The amount of methane in the gas phase decreases sharply as $\mathrm{T}$ or $\mathrm{f}_{2}$ increases. However, it seems reasonable to state that, where graphite occurs with iron-, wustite-, or fayalite-bearing assemblages, the contribution of methane to the coexisting gas phase will be significant. At temperatures below $400^{\circ} \mathrm{C}$, the contribution of methane is also important to a gas phase coexisting with more oxidized magnetite-graphite assemblages.

To apply the data to geological environments, it is convenient to recast the results presented in Figures (1-3) in order to specify values of $P_{i}$ as a function of temperature. This can be done by determining the value of $\mathrm{f}_{2}$ for a given solid-phase oxygen buffer by an equation of the type:

$$
\log \mathrm{f}_{\mathrm{O}_{2}}=-\frac{\mathrm{A}}{\mathrm{T}}+\mathrm{B}+\frac{\mathrm{C}\left(\mathrm{P}_{\mathrm{gas}}-1\right)}{\mathrm{T}}
$$

(Eugster and Wones, 1962). Thus, for a given buffer and a specified Pgas $\log \mathrm{f}_{\mathrm{O}_{2}}$ is a function only of $\mathrm{T}$. Values of $\mathrm{P}_{i}$ can then be calculated as unique functions of the temperature. ${ }^{2}$ 
2 The selection of a specific solid-phase buffer to establish the divariant relationship indicated in (9) between $T, P_{\text {gas }}$, and $\mathrm{f}_{\mathrm{O}_{2}}$ implies the addition of new components to the system $\mathrm{C}-\mathrm{H}-\mathrm{O}$ and the corresponding appearance of additional solid phases in equilibrium with graphite and gas. In order that the original trivariant system should become divariant, $(n+1)$ solid phases must appear for each additional $n$ components. Thus, the addition of $\mathrm{Fe}$ produces two-phase buffer assemblages (HM, MI, etc.), while addition of both $\mathrm{Fe}$ and $\mathrm{Si}$ requires three-phase buffers (QFM, QFI). In both cases, the new system now has $(n+3)$ components, $(n+2)$ solid phases, and a gas phase; under these conditions, it is divariant and all $P_{i}$ are explicitly determined by specifying only $P_{\text {gas }}$ and $T$.

Because of the rare occurrence of actual buffer assemblages in nature (Eugster and Wones, 1962, p. 115-116), it is most useful to use the buffers to establish extreme 1 imits of $\mathrm{f}_{\mathrm{O}_{2}}$ corresponding to the stability field of some index mineral (magnetite, fayalite, wistite, etc.); the corresponding extreme values of $P_{i}$ can then be calculated. Then, the occurrence of the mineral with graphite indicates 1 imiting values for composition of the coexisting gas phase.

Although the present discussion has emphasized $\mathrm{f}_{\mathrm{O}_{2}}$, the buffer technique is perfectly general (Eugster and Wones, 1962, p. 95). Additional volatile components may be introduced into the present calculations if new $f_{i}$ can be similarly limited by additional solid phases in the system. For example, inclusion of $\mathrm{f}_{\mathrm{S}_{2}}$ could be facilitated by introduction of the corresponding iron sulfides (Toulmin and Barton, 1964); consideration of $\mathrm{f}_{\mathrm{N}_{2}}$ might become desirable for study of certain nitride-bearing meteorite assemblages (Mason, 1958; Andersen et al., 1964; Keil and Anderson, 1965). 
Most igneous and metamorphic reactions apparentiy occur at values of $\mathrm{f}_{2}$ within the stability field of magnetite (Eugster and Wones, 1962). Figures (4-6) present values of $\log P_{i}$ as a function of temperature for three buffer combinations within this region: (1) the quartz-fayalite-magnetite (QFM) buffer (Fig. 4), which fixes the highest $\mathrm{f}_{\mathrm{O}_{2}}$ at which fayalite is stable; (2) the combined magnetite-iron (MI) and magnetite-wlstite (MW) buffers, which together specify the lowest $\mathrm{f}_{\mathrm{O}_{2}}$ for the existence of magnetite; and (3) the combined magnetite-iron (MI) and wistite-iron (WI) buffers; which correspond to the highest $E_{\mathrm{O}_{2}}$ for which metallic iron is stable.

Values of $\log P_{i}$ for the various species in a gas phase coexisting with the solid assemblage quartz + fayalite + magnetite + graphite are shown in Figure 4 as a function of temperature for $P_{\text {gas }}$ values of $1000 \mathrm{~b}$. and $10 \mathrm{~kb}$. The effect of a tenfold change in total gas pressure on the relative composition of the gas phase is slight; at both pressures, equilibrium is not possible above about $550^{\circ} \mathrm{C}$. The most important species in the gas phase are $\mathrm{CH}_{4}, \mathrm{CO}_{2}$, and $\mathrm{H}_{2} \mathrm{O}$; the latter two become dominant with increasing temperature.

The behavior of the gas phase at $\mathrm{P}_{\text {gas }}=1000 \mathrm{~b}$, in equilibrium with the two assemblages, magnetite + iron (below $560^{\circ} \mathrm{C}$ ) and magnetite + wustite (above $560^{\circ} \mathrm{C}$ ) is shown in Figure 5. Methane is dominant over much of the temperature range, but the assemblage itself becomes unstable above about $850^{\circ} \mathrm{C}$. The $\mathrm{f}_{2}$ values for these buffers (Fig. 5) represent minimum values for most geological processes. By contrast, at the same values of $\mathrm{P}_{\text {gas' }}$ the gas phase coexisting with the more reduced assemblages, magnetite + iron (below $560^{\circ} \mathrm{C}$ ) and wistite + iron (above $560^{\circ} \mathrm{C}$ ) is considerably different 
(Fig. 6). In this case, equilibrium is possible up to the limit of calculation, above $1200^{\circ} \mathrm{C}$. The contribution of methane is enhanced, and, at temperatures above $450^{\circ} \mathrm{C}, \mathrm{P}_{\mathrm{H}_{2}}>\mathrm{P}_{\mathrm{H}_{2} \mathrm{O}}$ and $\mathrm{P}_{\infty}>\mathrm{P}_{\mathrm{CO}_{2}}$. These curves represent the maximum $\mathrm{f}_{2}$ values for the occurrence of metallic iron, as in meteorites and in rare terrestrial rocks. Lower values of $\mathrm{f}_{\mathrm{O}_{2}}$ within the iron stability field will increase the reduced character of the gas phase.

Significance of Methane in Equilibrium with Graphite

Much speculation about the nature of hydrothermal fluids has considered a fluid phase as a mixture of $\mathrm{H}_{2} \mathrm{O}$ and $\mathrm{O}_{2}$. The present results indicate that, in addition, methane may be a significant species under a range of geologically possible conditions involving low to moderate temperatures, high gas pressures, and moderately low $\mathrm{f}_{2}$ values conditioned by the presence of graphite.

The importance of methane under such conditions is indicated by the data presented in Figures (7-8), which show the percentage of methane in a gas phase in equilibrium with graphite and various buffer assemblages. Since values of $P_{i}$ rather than $\log P_{i}$ are plotted, the assumption of ideal behavior will cause a proportionately greater uncertainty, but the relative relationships should not be affected. At $\mathrm{P}_{\text {gas }}=1$ b. (Fig. 7), more reducing values of $\mathrm{f}_{2}$ favor increased contribution of methane at higher temperatures. However, even at values of $\mathrm{f}_{\mathrm{O}_{2}}$ corresponding to the upper part of the magnetite stability field (approximately the NNO buffer), methane may still contribute 30 to 50 per cent of the value of $P_{\text {gas }}$. 
Higher gas pressures favor increased contribution of methane at higher temperatures; at $\mathrm{P}_{\text {gas }}=1000 \mathrm{~b}$. (Fig. 8), methane accounts for more than half of the value of $P_{\text {gas }}$ within the stability fields of fayalite and wustite. Increasing $\mathrm{P}_{\text {gas }}$ above $1000 \mathrm{~b}$. will correspondingly increase the relative contribution of methane.

With increasing temperature, methane gradually disappears as $\mathrm{H}_{2} \mathrm{O}$ and $\infty_{2}$ became dominant. The relative amounts of the latter two species depend on $P_{\text {gas }}$, as indicated in Figure 9, where values for all $P_{i}$ are plotted as a function of $\mathrm{T}$ for the $\mathrm{QFM}$ and $\mathrm{MI}-\mathrm{WI}$ buffers. At $\mathrm{P}_{\text {gas }}=1 \mathrm{~b}$., $\mathrm{CH}_{4}$ and $\mathrm{H}_{2}$ are dominant at low temperatures; with increasing temperature, $\mathrm{P}_{\mathrm{H}_{2} \mathrm{O}}$ passes through a maximum and $\mathrm{CO}_{2}$ becomes the dominant species. By contrast, at $\mathrm{P}_{\text {gas }}=1000 \mathrm{~b}$., (Fig. 10), both $\mathrm{H}_{2}$ and $\infty$ are negligible. With increasing temperature, $\mathrm{P}_{\mathrm{H}_{2}} \mathrm{O}$ and $\mathrm{P}_{\mathrm{CO}_{2}}$ increase continually as $\mathrm{P}_{\mathrm{CH}_{4}}$ decreases, with $\mathrm{P}_{\mathrm{H}_{2} \mathrm{O}}$ always greater than $\mathrm{P}_{\mathrm{CO}_{2}}$. Pressures above $1000 \mathrm{~b}$. will increase the preferential production of water with decreasing $\mathrm{P}_{\mathrm{CH}_{4}}$, although somewhat higher temperatures will be required for complete conversion.

A significant feature of these data is the rapid decrease in $\mathrm{P}_{\mathrm{CH}_{4}}$ with increasing temperature. For example, at $\mathrm{P}_{\text {gas }}=1 \mathrm{~b}$. (Fig. 9), $\mathrm{P}_{\mathrm{CH}_{4}}$ drops from $0.7 \mathrm{~b}$. to virtually zero between about $225^{\circ}$ and $325^{\circ} \mathrm{C}$ along the QFM buffer; even at lower values of $\mathrm{f}_{\mathrm{O}_{2}}$ along the $\mathrm{MI}$-WI buffer, $\mathrm{P}_{\mathrm{CH}_{4}}$ is reduced from $0.6 \mathrm{~b}$. to zero between $450^{\circ}$ and $650^{\circ} \mathrm{C}$. Similar but less sudden decreases occur at $\mathrm{P}_{\text {gas }}=1000 \mathrm{~b}$. (Fig. 10); on both buffers, a temperature interval of only $150^{\circ} \mathrm{C}:$ is sufficient to reduce $\mathrm{P}_{\mathrm{CH}_{4}}$ from about $600 \mathrm{~b}$. to zero. Such rapid changes in the composition of the gas phase with changing temperature suggest that the principal difficulty in estimating gas compositions from natural mineral assemblages will be uncertainties in temperature; the effects of uncertainties in $\mathrm{P}_{\text {gas }}$ will be minor in comparison. The application of these data to geological 
assemblages will thus require very accurate temperature data, since a change of only $200^{\circ} \mathrm{C}$ is sufficient to convert a gas phase composed almost entirely of methane into one in which $\mathrm{H}_{2} \mathrm{O}$ and $\mathrm{O}_{2}$ together constitute more than 80 per cent of $\mathrm{P}_{\text {gas }}$. The implications of these results for a model of production of the terrestrial atmosphere by reactions within the earth is discussed later. The detection and identification of methane in liquid inclusions and in some graphite-bearing rocks provides experimental support for the conclusion that methane may be a significant constituent of natural hydrothermal fluids. Methane has been reported as a minor constituent of liquid inclusions in quartz-bearing pegmatites (Elinson and Polykovskii, 1963a, 1963b) and in large amounts in inclusions in alkaline igneous rocks, associated with small amounts of organic matter (Petersil'ye et al., 1961). At least 5000 ppm of methane and minor amounts of other hydrocarbons were evolved from graphite from a Precambrian quartz-graphite schist (Hoering and Hart, 1964). Further studies of this type would be very desirable. Maximum $\underline{\underline{P}}_{\text {gas }}$ - Temperature Curves for Graphite-Bearing Assemblages In the calculations presented, it was often observed that, under conditions of relatively high $\mathrm{T}$ and $\mathrm{f}_{\mathrm{O}_{2}}$, no solutions were possible to the system of Equations $(1-5,8)$. This incompatibility arises from the fact that values of $\mathrm{P}_{\mathrm{CO}_{2}}$ and $\mathrm{P}_{\infty}$ are (for the ideal-gas model) dependent only on $\mathrm{T}$ and $\mathrm{f}_{\mathrm{O}_{2}}$ and completely independent of $\mathrm{P}_{\text {gas }}{ }^{\cdot}$ It is therefore possible, as $\mathrm{T}$ or $\mathrm{f}_{2}$ increases, to generate a condition where the quantity, $\left(\mathrm{P}_{\mathrm{OO}_{2}}+\mathrm{P}_{\mathrm{CO}}\right)$ exceeds the specified, value of $\mathrm{P}_{\text {gas }}$. Such a condition is impossible and the equations become insoluble.

Under conditions of specified $T$ and $P_{\text {gas }}$, this limit is reached by increasing $\mathrm{f}_{2}$ (Figs. 1-3). In later calculations the use of a buffer to 
control $\mathrm{f}_{2}$ as a function of $\mathrm{T}$ introduces an additional equation involving $\mathrm{f}_{\mathrm{O}_{2}}$. Thus, two simultaneous equations must be satisfied for equilibrium to be maintained. For graphite,

$$
c+o_{2}=\infty_{2}
$$

$$
\mathrm{K}_{1}=\mathrm{f}_{\mathrm{O}_{2}} / \mathrm{f}_{\mathrm{O}_{2}}
$$

The solid-phase buffer has an equation of the form

$$
X+Y=Z+O_{2}
$$

$$
\mathrm{K}_{10}=\mathrm{f}_{\mathrm{O}_{2}}
$$

where $X, Y$, and $Z$ are solid phases.

For an ideal gas, $\mathrm{P}_{\mathrm{OO}_{2}}=\mathrm{K}_{1} \mathrm{f}_{\mathrm{O}_{2}}$. Further, the system requires that

$$
\mathrm{P}_{\text {gas }} \geq \mathrm{P}_{\mathrm{O}_{2}}=\mathrm{K}_{1} \mathrm{~K}_{10}=\mathrm{K}_{1} \mathrm{f}_{\mathrm{O}_{2}}
$$

No solutions will exist for values of $T, P_{\text {gas }}$ and $f_{O_{2}}$ for which

$$
\log \mathrm{P}_{\text {gas }} \leq \log \mathrm{P}_{\mathrm{O}_{2}}=\log \mathrm{K}_{1}+\log \mathrm{P}_{\mathrm{O}_{2}}
$$

or,

$$
\log \mathrm{P}_{\mathrm{O}_{2}} \geq \log \mathrm{P}_{\text {gas }}-\log \mathrm{K}_{1}
$$


With increasing $\mathrm{T}$ or $\mathrm{f}_{\mathrm{O}_{2}}$, such a limit occurs below $1500^{\circ} \mathrm{K}$ for all but the more reducing buffers and corresponds to the appearance of disequilibrium between graphite and the solid-phase buffer assemblage. In general, the more oxidizing the buffer, the lower the temperature at which it becomes unstable with respect to graphite. Actual disequilibrium temperatures will be lower than suggested by (11) because of the contribution ố other species to $\mathrm{P}_{\text {gas }}$. Calculation of the exact disequilibrium temperature for different values of $\mathrm{P}_{\text {gas }}$ establishes a maximum temperature for equilibrium between graphite and each buffer assemblage. These points form a series of univariant curves in $\mathrm{P}_{\text {gas }}-\mathrm{T}-\mathrm{f}_{\mathrm{O}_{2}}$ space and may be presented as projections onto the $\mathrm{P}_{\text {gas }}{ }^{-\mathrm{T}}$ plane (Fig. 11).

Each curve fixes only the maximum temperature for existence of the buffer assemblage with graphite; the phases will be in equilibrium at all temperatures below the curve. For instance, the assemblage, hematite + magnetite + graphite is stable at all temperatures and pressures to the left of Curve (1) (Fig. 11); the value of $\mathrm{f}_{\mathrm{O}_{2}}$ in this region is specified by the HM buffer. As Curve (1) is reached with increasing temperature, the three phases become unstable and one must disappear. Three paths are possible: (1) graphite is removed by oxidation, and the assemblage hematite + magnetite continues to buffer $\mathrm{f}_{2}$ at temperatures to the right of the curve; (2) hematite is reduced to magnetite, in which case magnetite and graphite coexist to the right of the curve and do not constitute an $\mathrm{f}_{2}$ buffer; (3) magnetite is oxidized to hematite, producing the assemblage hematite + graphite, which also does not buffer $\mathrm{f}_{\mathrm{O}_{2}}$. If graphite remains in the assemblage at temperatures to the right of the curve, the buffering ability of the system is destroyed and two 
assembiages are possible: hematite + graphite at high $\mathrm{f}_{\mathrm{O}_{2}}$ and magnetite + graphite at low $\mathrm{fO}_{2}$.

Similar arguments apply to the other curves, particularly to Curve (3), which indicates the maximum stability temperature for the assemblage, quartz + fayalite + magnetite + graphite. The four-phase assemblage, stable to the left of Curve ( 3 ), buffers $\mathrm{f}_{\mathrm{O}_{2}}$ rigorously. To the right of the curve, four three-phase assemblages are possible: (a) quartz + fayalite + magnetite;

(b) quartz + fayalite + graphite; (c) quartz + magnetite + graphite; (d) fayalite + magnetite + graphite. Only assemblage (a) is a rigorous oxygen buffer.

In general, for each curve, the region to the left denotes equilibrium between the solid-phase oxygen buffer, graphite, and the gas phase. As the curve is crossed with increasing temperature, the buffer assemblage and graphite become unstable, and the character of the system at higher temperatures depends on whether or not graphite disappears. If graphite is oxidized, the solid-phase buffer still controls $\mathrm{f}_{\mathrm{O}_{2}}$, but another degree of compositional freedom is added to the gas phase by the disappearance of graphite. If graphite remains, the solid phases no longer constitute an oxygen buffer and the value of $\mathrm{f}_{2}$ can be specified only within wide limits.

The curves have considerable application to geological problems, for they provide upper temperature limits for the existence of certain mineral assemblages in equilibrium with graphite and gas. They have the added advantage of being extremely insensitive to changes in $\mathrm{P}_{\text {gas }}$ above a moderate pressure. The difficulty . in applying the curves to natural assemblages lies in the necessity of identifying several solid phases in the same specimen and of demonstrating 
that they are in fact in equilibrium (see Zen, 1963). In addition, even if it can be shown that a given curve has in fact been exceeded, careful study is necessary to distinguish between the different petrologic interpretations deriving from the presence or absence of graphite in the assemblage.

The fact that most present solid-buffer data involve iron-bearing minerals has restricted their application to metamorphosed iron formations containing some of the required assemblages (Gundersen and Schwartz, 1962; Zen, 1963; French, 1965). However, numerous possibilities exist for study of graphite and opaque accessory minerals in igneous and metamorphic rocks (see, e.g., Chinner, 1960; Buddington and Lindsley, 1964).

Progressive Metamorphism of Graphite-Bearing Sediments

There has been much consideration of the role of water and $\mathrm{CO}_{2}$ in metamorphism, since many of the observed mineral transformations can be expressed by reactions involving these volatile components. Many speculations about the nature of hydrothermal fluids have presupposed a gas phase in which these two species are dominant. Even though other components such as methane may assume a significant role under certain conditions, it is worthwhile to consider the relationship between $\mathrm{P}_{\mathrm{H}_{2} \mathrm{O}}$ and $\mathrm{P}_{\mathrm{O}_{2}}$ in a gas phase in equilibrium with graphite under conditions corresponding to progressive metamorphism.

The presence of graphite or amorphous carbon in metamorphosed sediments has been proposed to explain two observed characteristics of metamorphosed rocks: (1) apparent relative reduction of mineral assemblages with increasing metamorphic grade, corresponding to an increase in the $\mathrm{Fe}^{2+} / \mathrm{Fe}^{3+}$ ratio (Shaw, 1956; Zen, 1963; Miyashiro, 1964), and (2) preservation of apparent1y steep gradients in $\mathrm{P}_{\mathrm{O}_{2}}$ over short distances, particularly between adjacent layers of differing composition (Chinner, 1960; Kranck, 1961; Zen, 1963). 
Application of the present model requires only the development of graphite during metamorphism, possibly through recrystallization of original organic matter (French, 1964; Hoering and Hart, 1964). Because of the low gram-molecular weight of graphite, a small amount will be ample for extensive equilibration; such amounts are common in metamorphosed sediments (see, e.g., Miyashiro, 1964).

Construction of $\mathrm{P}_{\mathrm{H}_{2}} \mathrm{O}^{-} \mathrm{P}_{\mathrm{CO}_{2}}$ plots from the numerical results requires only the selection of $\mathrm{P}_{\mathrm{CO}_{2}}$ as an independent variable instead of $\mathrm{f}_{\mathrm{O}_{2}}$. Then, for a given temperature and $\mathrm{P}_{\text {gas }}, \mathrm{P}_{\mathrm{H}_{2} \mathrm{O}}$ can be plotted as a function of $\mathrm{P}_{\mathrm{O}_{2}}$ to form a series of isothermal curves (Figs. 12-13). Each point on a curve corresponds to a condition in which all $\mathrm{P}_{i}$ (including $\mathrm{P}_{\mathrm{O}_{2}}$ ) are explicitly specified.

At $\mathrm{P}_{\text {gas }}=100$ bars (Fig. 12), the $\mathrm{P}_{\mathrm{H}_{2}} \mathrm{O}^{-\mathrm{P}_{\mathrm{CO}_{2}}}$ i sotherms between $300^{\circ}$ and $1500^{\circ} \mathrm{K}$ are a series of asymmetric curves which pass through maxima in the region of 5 to $30 \mathrm{~b} \cdot \mathrm{P}_{\mathrm{O}_{2}}$. Additional curves corresponding to data derived from the $\mathrm{f}_{\mathrm{O}_{2}}-\mathrm{T}$ relations for the solid-phase oxygen buffers have been superimposed on the isotherms.

The oblique line at the top represents the locus of points for the condition, $\mathrm{P}_{\mathrm{H}_{2} \mathrm{O}}+\mathrm{P}_{\mathrm{OO}_{2}}=100 \mathrm{~b}$., and the vertical distance between this line and any point on an isotherm represents the total pressure of other species in the gas phase. At low values of $\mathrm{P}_{\mathrm{CO}_{2}}$, this difference is large for all temperatures and reflects the dominance of methane under conditions of low $\mathrm{P}_{\mathrm{O}_{2}}$. At higher temperatures, the difference is large for all values of $\mathrm{P}_{\mathrm{CO}_{2}}$ because of the increasing contribution of $\mathrm{H}_{2}$ and $\mathrm{CO}$ to the gas phase. An increase in $\mathrm{P}_{\text {gas }}$ from $100 \mathrm{~b}$. to $1000 \mathrm{~b}$. (Fig. 13) produces a slight shift in the isotherms toward higher values of $\mathrm{P}_{\mathrm{H}_{2} \mathrm{O}}$ and $\mathrm{P}_{\mathrm{CO}_{2}}$; however, the 
general relations are unchanged. Increases in $\mathrm{P}_{\text {gas }}$ above $1000 \mathrm{~b}$. will produce relatively smaller shifts.

These relations have several implications for study of the progressive metamorphism of graphite-bearing sediments. First, graphite cannot coexist with pure water under the conditions indicated; even at the lowest temperatures, the highest water content permitted is about $0.85 \mathrm{P}_{\text {gas }}$. By contrast, graphite can coexist over a wide temperature range with a water-free atmosphere containing chiefly $\infty_{2}$.

Second, for a fixed temperature and $\mathrm{P}_{\text {gas }}$, the values of $\mathrm{P}_{\mathrm{H}_{2} \mathrm{O}}$ and $\mathrm{P}_{\mathrm{O}_{2}}$ cannot vary independently but must correspond to points along an isotherm. As $\mathrm{P}_{\mathrm{CO}_{2}}$ increases, $\mathrm{P}_{\mathrm{H}_{2} \mathrm{O}}$ increases at first, passes through a maximum in the region where $\mathrm{P}_{\mathrm{H}_{2} \mathrm{O}}>\mathrm{P}_{\mathrm{O}_{2}}$, then decreases to zero.

For the complete temperature range under discussion, low values of $\mathrm{P}_{\mathrm{CO}_{2}}$ (less than $0.05 \mathrm{P}_{\text {gas }}$ ) reflect a methane-rich atmosphere existing under conditions of relatively low $\mathrm{P}_{\mathrm{O}_{2}}$. With increasing temperature, however, the gas phase becomes progressively depleted in $\mathrm{H}_{2} \mathrm{O}$ and $\infty_{2}$, and $\mathrm{H}_{2}$ and $\infty$ become important. For this reason, the assumption that $\mathrm{P}_{\text {gas }}=\mathrm{P}_{\mathrm{OO}_{2}}+\mathrm{P}_{\mathrm{H}_{2}} \mathrm{O}$ is significantly in error over a wide range of metamorphic temperatures. At $600^{\circ} \mathrm{K}\left(327^{\circ} \mathrm{C}\right)$, the contribution of other components will exceed 10 per cent of $\mathrm{P}_{\text {gas }}$ for values of $\mathrm{P}_{\mathrm{OO}_{2}} \leq 0.4 \mathrm{P}_{\text {. gas }}$. At temperatures above $1000^{\circ} \mathrm{K}$ $\left(727^{\circ} \mathrm{C}\right)$, a similar error is present for all values of $\mathrm{P}_{\mathrm{CO}_{2}}$. Comparing the solid-phase buffer curves with the isothermal $\mathrm{P}_{\mathrm{H}_{2}} \mathrm{O}^{-\mathrm{P}_{\mathrm{CO}}}$ curves (Figs. 12-13) indicates that reaction with graphite during rising temperature will produce progressively reduced mineral assemblages. For instance, at $\mathrm{P}_{\text {gas }}=1000 \mathrm{~b}$. (Fig. 13), temperatures between $100^{\circ}$ and $200^{\circ} \mathrm{C}$ are sufficient to convert original hematite to magnetite if graphite is 
present. Such a mechanism has been suggested to explain the development of magnetite from original hematite in slightly metamorphosed sedimentary iron formations (Zen, 1963; LaBerge, 1964). More extreme reduction may be attained at higher temperatures; the development of fayalite in contactmetamorphosed iron formation may be conditioned by the presence of graphite (Gundersen and Schwartz, 1962; French, 1965). The rare occurrences of wustite and native iron in terrestrial rocks (Walenta, 1960; Melson and Switzer, 1965) also appear associated with graphite which, at igneous temperatures, could produce extremely reducing conditions. It should be added that, when such reduced minerals are observed, the contribution to $P_{\text {gas }}$ of species other than $\mathrm{H}_{2} \mathrm{O}$ and $\omega_{2}$ may be significant.

A specific model of particular interest is the progressive metamorphism of a sediment containing graphite and original interstitial water under conditions where the system is either completely closed or open only to water (Yoder, 1955; Thompson, 1955). It has been pointed out by earlier investigators (Eugster, 1959; Miyashiro, 1964) that, under these initial conditions, the resultant gas phase must undergo reduction in order to be in equilibrium with the observed mineral assemblages.

In applying the present calculations to such a system, we may express the additional constraint by saying that, whatever the composition of the gas phase during metamorphism, the total $\mathrm{H} / \mathrm{O}$ ratio is $\mathrm{fixed}$ at $2 / 1$ for both the closed and water-permeable systems. Such arbitrary selection of elemental ratios to reduce variance has been applied previously in analogous calculations (Suess, 1962; Dayhoff et al., 1964). This additional restriction makes it possible to calculate all $\mathrm{P}_{i}$ as explicit functions of $\mathrm{T}$ and $\mathrm{P}_{\text {gas }}$ only. In addition to the equilibrium relations (Eqs. 1-5), the requirements of 
materials balance may be written (Suess, 1962):

$$
\begin{aligned}
& \mathrm{H}=4 \mathrm{P}_{\mathrm{CH}_{4}}+2 \mathrm{P}_{\mathrm{H}_{2}}+2 \mathrm{P}_{\mathrm{H}_{2} \mathrm{O}} \\
& \mathrm{O}=\mathrm{P}_{\mathrm{H}_{2} \mathrm{O}}+\mathrm{P}_{\mathrm{OO}}+2 \mathrm{P}_{\mathrm{CO}_{2}}+2 \mathrm{P}_{\mathrm{O}_{2}}
\end{aligned}
$$

Since $\mathrm{H} / \mathrm{O}=2 / 1$,

$$
\begin{aligned}
& 4 \mathrm{P}_{\mathrm{CH}_{4}}+2 \mathrm{P}_{\mathrm{H}_{2}}+2 \mathrm{P}_{\mathrm{H}_{2} \mathrm{O}}=2\left(\mathrm{P}_{\mathrm{H}_{2} \mathrm{O}}+\mathrm{P}_{\mathrm{OO}}+2 \mathrm{P}_{\mathrm{CO}_{2}}+2 \mathrm{P}_{2}\right) \\
& 2 \mathrm{P}_{\mathrm{OO}_{2}}+\mathrm{P}_{\infty}-2 \mathrm{P}_{\mathrm{CH}_{4}}-2 \mathrm{P}_{\mathrm{H}_{2}}+2 \mathrm{P}_{\mathrm{O}_{2}}=0
\end{aligned}
$$

Equations (1-5) and (12) together constitute a system of six equations for the six unknown $\mathrm{P}_{\mathrm{i}}$; explicit solutions are therefore possible once $\mathrm{T}$ and $\mathrm{P}_{\text {gas }}$ are fixed. In practice, however, the calculations became involved because of the appearance of a quartic equation in $\mathrm{P}_{\mathrm{H}_{2}}$. Therefore, a simpler procedure was adopted by specifying $\mathrm{T}$ and $\mathrm{f}_{\mathrm{O}_{2}}$ instead. $\mathrm{P}_{\text {gas }}$ was calculated by summation at the end of the process and values of $P_{i}$ were obtained by interpolation for any selected $\mathrm{P}_{\text {gas }}$.

Under these conditions, graphite becomes a true oxygen buffer, since the value of $\mathrm{f}_{\mathrm{O}_{2}}$ maintained in the gas phase depends only on $\mathrm{T}$ and $\mathrm{P}_{\text {gas }}$. Values of $\mathrm{f}_{2}$ fixed by graphite in this system for values of $\mathrm{P}_{\text {gas }}$ of $1 \mathrm{~b}$. and $2000 \mathrm{~b}$. (Fig. 14) are very close to analogous values calculated earlier for a gas phase composed only of $\mathrm{CO}_{2}$ and $\mathrm{CO}$ (French and Eugster, 1965). Both sets of $\mathrm{f}_{\mathrm{O}_{2}}-\mathrm{T}$ curves have shallower slopes than do the curves for the iron-bearing solid phase buffers. Thus, in both cases, more reduced mineral 
assemblages will appear with increasing temperature, in agreement with the general conclusions discussed above (Figs. 12-13).

The interpolated values of $P_{i}$ are shown in Figure 15 as a function of temperature for $\mathrm{P}_{\text {gas }}=1000 \mathrm{~b}$. Below about $1000^{\circ} \mathrm{C}$, the gas phase consists chiefly of $\mathrm{H}_{2} \mathrm{O}, \infty_{2}$, and $\mathrm{CH}_{4}$; the water content decreases sharply with rising temperature. $\mathrm{P}_{\mathrm{CH}_{4}}$ and $\mathrm{P}_{\mathrm{CO}_{2}}$ are approximately equal and pass through maxima where each constitutes about $0.25 \mathrm{P}_{\text {gas }}$. Above about $1000^{\circ} \mathrm{C}, \mathrm{H}_{2}$ and $\mathrm{CO}$ become dominant, although the gas phase still contains significant amounts of all five species. The $\mathrm{f}_{\mathrm{O}_{2}}-\mathrm{T}$ curve for this system intersects progressively reduced buffer curves at slight angles with rising temperature. In this idealized case, fayalite would form in rocks of the proper composition at about $540^{\circ} \mathrm{C}$, whstite at $850^{\circ} \mathrm{C}$, and metallic iron at $1160^{\circ} \mathrm{C}$.

Mineral Assemblages in Meteorites

Numerous recent studies of the mineralogy and petrology of meteorites have attempted to apply mineralogical data to estimate conditions of formation of the various classes (see, e.g., Ringwood, 1961; Wood, 1962, 1963; Mueller, 1964). Considerable speculation has involved estimates of $\mathrm{P}_{\mathrm{O}_{2}}$ and possible theories for evolution of the various types under differing degrees of reduction.

The general relationships between graphite and the composition of the coexisting gas phase suggest that the occurrence of graphite as an accessory mineral in meteorites is of great significance in attempting to evaluate conditions of formation. Graphite has been observed in several classes of meteorites, most prominently in the irons, but also in smaller amounts in stony meteorites, notably chondrites (Mason, 1958; Krinov, 1960; Ramdohr, 1962 ; Andersen, et a1., 1964; Vdovykin, 1964). 
In particular, the assemblage graphite + nickel-iron is common and widespread in both iron and stony meteorites. The results of the present study suggest that this assemblage formed under extremely reducing conditions in which methane may have been a dominant component of the coexisting gas phase, even at relatively high temperatures. For instance, at $\mathrm{P}_{\text {gas }}=1000 \mathrm{~b}$. (Figs. 5, 8), the upper limit of stability of iron + graphite is fixed by the MI and WI buffers; at all temperatures below $1000^{\circ} \mathrm{C}, \mathrm{P}_{\mathrm{CH}_{4}}$ exceeds $500 \mathrm{~b}$. Lower values of $\mathrm{P}_{\mathrm{O}_{2}}$ within the iron stability field will increase the contribution of methane, even at higher temperatures. The reported occurrence of quartz and tridymite in several iron-bearing meteorites (see Anders, 1964) suggests that at least some meteorites have developed at very low values of $\mathrm{P}_{\mathrm{O}_{2}}$ below the QFI buffer where silica and iron can coexist without formation of fayalite. At these values of $\mathrm{P}_{\mathrm{O}_{2}}$ (Fig. 8) the same $\mathrm{P}_{\mathrm{CH}_{4}}$ could be maintained at temperatures in excess of $1200^{\circ} \mathrm{C}$.

The use of buffer curves for pure iron in this discussion will not change the general conclusions. Even though the nickel-iron in meteorites will be in equilibrium with oxide at higher $\mathrm{f}_{\mathrm{O}_{2}}$ values than pure iron, calculations suggest that the effect will not be large for small nickel contents (Olsen, 1959). Furthermore, the metal phase in at least one class of meteorites, the basaltic achondrites, is strongly depleted in nickel (Duke, 1965). 
A POSSIBLE MECHANISM FOR EVOLUTION OF THE TERRESTRIAL ATMOSPHERE

The origin and evolution of the atmosphere and oceans are of profound importance in consideration of such problems as the origin of the earth and solar system, the nature of ancient geological processes, and the origin of life on earth. The purpose of the present discussion is not to review or evaluate the numerous theories and voluminous literature on the subject (for summaries, see Rutten, 1962; Brancazio and Cameron, 1964; Donn et al., 1965), but to discuss certain possible processes related to the occurrence of graphite and other minerals in the earth.

Three general methods have been used by earlier investigators to estimate the character of the primordial or Precambrian atmosphere existing at a time before deposition of most of the presently preserved sedimentary record :

(1) Calculation of the amounts of volatile compounds now present in the atmosphere and oceans which must have been produced by processes other than rock weathering (Rubey, 1951); such "excess volatiles" must either have been present in an original atmosphere or must have been added by gradual outgassing from the interior of the earth during geologic time.

(2) Use of thermodynamic equilibria to determine relative amounts of different volatile species in the atmosphere (Rubey, 1951; Holland, 1962, 1964). Such results are of limited value because they may not consider all possible equilibria, and because the equilibrium constants involved are strongly temperature-dependent. Temperatures existing in ancient atmospheres and within the primordial earth are speculative and the arbitrary selection of high temperatures is not justified. Furthermore, if low surface temperatures 
are postulated, one cannot assume that equilibrium is established, either within the atmosphere or between the atmosphere and surface rocks, any more than it is at present.

(3) Study of ancient sedimentary rocks to estimate the character of the atmosphere in which they formed. Many studies have cited the occurrence of reduced minerals in sediments as evidence that the Precambrian atmosphere was reduced with respect to the present one (Rankama, 1958; Holland, 1962; Lepp and Goldich, 1964). These studies, while valuable, are hampered by two conditions. First, there is no evidence that detrital minerals are necessarily equilibrated with the atmosphere during erosion, transport, and deposition. Such equilibration is generally not attained at present; magnetite, iron-titanium oxides, and ferrous silicates are common detrital accessory minerals, although they should oxidize to hematite or iron hydroxides in the present atmosphere. Second, the effects of burial, diagenesis, and lowgrade metamorphism on the mineralogy are difficult to recognize. The sediment may be effectively insulated from the atmosphere in a local reducing environment soon after deposition. Further, the presence of organic matter or graphite may produce reduced mineral assemblages with very slight increases in temperature, destroying traces of original equilibrium with the atmosphere.

It has been generally assumed that a reducing atmosphere lacking free oxygen existed at some point in the history of the primordial earth. Such an atmosphere would be required for the development and preservation of organic compounds and their eventual combination into primitive forms of 1ife (see Rubey, 1951; Urey, 1952; Oparin, 1957; Miller and Urey, 1959; Holland, 1962; Rutten, 1962). The exact character of this atmosphere is not agreed upon; it has variously been proposed that $\mathrm{CH}_{4}, \mathrm{OO}_{2}, \mathrm{~N}_{2}$ and $\mathrm{H}_{2} \mathrm{O}$ were dominant species. 
Ho1land (1962) proposed a three-stage model for development of the atmosphere through outgassing of the original crust: (1) an atmosphere formed in equilibrium with metallic iron at $1200^{\circ} \mathrm{C}$, composed of $\mathrm{CH}_{4}, \mathrm{H}_{2}$ and minor $\mathrm{H}_{2} \mathrm{O}$ and $\mathrm{N}_{2}$; liquid $\mathrm{H}_{2} \mathrm{O}$ would also exist on the surface. (2) A later stage containing dominant $\mathrm{N}_{2}$ and minor $\mathrm{H}_{2} \mathrm{O}$ and $\mathrm{CO}_{2}$, produced by equilibrium with magnetite in a more oxidized crust; (3) A final stage developed from photosynthetic production of oxygen and corresponding to the present atmosphere.

This model has two serious objections. First, the temperature of $1200^{\circ} \mathrm{C}$, while not unreasonable, is arbitrary; because of the strong dependence of equilibria on temperature, arbitrary selection of temperature strongly conditions the gas compositions obtained. Second, the equilibria in the atmosphere (at an assumed temperature of $298^{\circ} \mathrm{K}$ ) may not be established, and the calculated compositions may not be attained.

The present discussion is somewhat similar to Holland's model, and considers the problem of converting an original methane-rich atmosphere into water and $\mathrm{CO}_{2}$ through equilibria between a gas phase and accessory minerals existing to moderate depths within the primordial earth. In the proposed mechanism, original methane reacts with graphite and ferric-iron-bearing phases at temperatures in excess of $600^{\circ} \mathrm{C}$ to depths of a few hundred kilometers, producing water and $\mathrm{CO}_{2}$ which are removed to a cool surface to form oceans and atmosphere. Such a mechanism does not require low-temperature equilibrium between atmosphere and the surface rocks or between the different species within the atmosphere itself; the surface temperature can be low enough to prevent re-equilibration of water and $\mathrm{CO}_{2}$ to produce methane again.

Such a mechanism is independent of any detailed assumptions about the composition, thermal history, and structure of the primordial earth. Its 
operation requires only a source of sufficient original methane and accessory minerals, sufficient heating to attain temperatures of $600^{\circ}$ to $1000^{\circ} \mathrm{C}$ at moderate depths, and some mechanism for removing the product gases to the surface through fissure systems or by volcanism. In the present discussion, it is assumed that all of the "excess volatile" water and $\mathrm{CO}_{2}$ (Rubey, 1951) originated by this mechanism; it will be found that the material requirements for even this extreme case are not excessive. Despite the obvious oversimplifications, this mechanism is consistent with a variety of earth models, even though it neglects such significant problems as the source of the original methane, the time required for the transformation, and the presence or absence of a differentiated core in the primordial earth during the process.

Data from the present study indicate that methane originally in equilibrium with graphite will be converted to water and $\mathrm{CO}_{2}$ with increasing temperatures; at higher values of $\mathrm{P}_{\text {gas }}$, water will form in excess of $\mathrm{CO}_{2}$ (Figs. 9-10). At $\mathrm{P}_{\text {gas }}=1000 \mathrm{~b}$., temperatures above $600^{\circ} \mathrm{C}$ are sufficient for complete conversion at values of $\mathrm{P}_{\mathrm{O}_{2}}$ within the stability field of magnetite ( $Q F M$ buffer) (Fig. 10). At minimum values of $\mathrm{P}_{\mathrm{O}_{2}}$ within the magnetite field, the maximum temperature is about $950^{\circ} \mathrm{C}$. Increasing $\mathrm{P}_{\text {gas }}$ to $100 \mathrm{~kb}$. increases the maximum temperature to about $1250^{\circ} \mathrm{C}$. In any case, significantly lower temperatures will suffice if water and $\infty_{2}$ are continually removed, allowing the reaction to proceed to completion.

MacDonald (1959) has calculated temperature distributions resulting from radioactive heating in a number of primordial earth models as a function of time after formation. The numerical results may be subject to later modification (Wasserburg et al., 1964) but it appears that, for numerous possible models, temperatures of $800^{\circ}$ to $1500^{\circ} \mathrm{C}$ could be attained at 100 to $300 \mathrm{~km}$. depth within 
$10^{9}$ years after formation. In fact, MacDonald has suggested (1959, p. 19871989) that initial temperatures well above these values could have been reasonably attained during formation of the earth by accretion. If this were the case, methane would have been converted to water and $\mathrm{CO}_{2}$ almost simultaneously with formation of the earth and would not have existed within the body for any significant length of time. In any case, it appears that the temperatures required could have been generated, even though an exact specification of the temperature distribution in the body is not possible.

A wide variety of heterogeneous reactions may occur within the earth to convert methane into water and $\mathrm{CO}_{2}$ through reaction with solid phases; the following are some simple examples:

$$
\mathrm{CH}_{4}+2 \mathrm{Fe}_{3} \mathrm{O}_{4}+3 \mathrm{SiO}_{2}=3 \mathrm{Fe}_{2} \mathrm{SiO}_{4}+\mathrm{C}+2 \mathrm{H}_{2} \mathrm{O}
$$

$$
\mathrm{CH}_{4}+2 \mathrm{Fe}_{3} \mathrm{O}_{4}+6 \mathrm{SiO}_{2}=6 \mathrm{FeSiO}_{3}+\mathrm{C}+2 \mathrm{H}_{2} \mathrm{O}
$$

$$
\mathrm{CH}_{4}+2 \mathrm{Fe}_{3} \mathrm{O}_{4}=6 \mathrm{FeO}+\mathrm{C}+2 \mathrm{H}_{2} \mathrm{O}
$$

$$
2 \mathrm{CH}_{4}+\mathrm{Fe}_{3} \mathrm{O}_{4}=3 \mathrm{Fe}+2 \mathrm{C}+4 \mathrm{H}_{2} \mathrm{O}
$$

Actual reactions will probably involve more complex ferrous-ferric silicates such as garnets, amphiboles, and micas, but the stoichiometry will be similar to these examples. The subsequent calculations are made using magnetite as a reactant and assuming a conversion equation of the form, 
where $R$ designates a reduced phase such as fayalite, ferrosilite, wistite, or iron. The necessary $\mathrm{CO}_{2}$ may be formed by reaction of a small amount of product water with graphite, i.e.,

$$
\mathrm{C}+2 \mathrm{H}_{2} \mathrm{O}=\mathrm{CO}_{2}+2 \mathrm{H}_{2}
$$

The volatile products are transported to the surface, where water condenses and $\mathrm{CO}_{2}$ and $\mathrm{H}_{2}$ are incorporated into the original atmosphere, together with an undetermined amount of $\mathrm{N}_{2}$. If the rate of introduction of $\mathrm{H}_{2}$ is slow, it may escape from the atmosphere without building up a high partial pressure (Holland, 1962).

The amounts of "excess volatile" water and $\mathrm{CO}_{2}$ which should be produced are (Rubey, 1951):

$$
\begin{aligned}
& \mathrm{H}_{2} \mathrm{O}: 1.66 \times 10^{24} \mathrm{gm} .=9.21 \times 10^{22} \text { moles } \\
& \mathrm{CO}_{2}: 9.1 \times 10^{22} \mathrm{gm} .=2.07 \times 10^{21} \text { moles }
\end{aligned}
$$

From (17) and (18), the materials balance becomes (in moles):

$$
\begin{array}{llll} 
& \multicolumn{2}{c}{\text { Reactants }} & \multicolumn{2}{c}{\text { Products }} \\
\cline { 2 - 2 } \mathrm{CH}_{4} & 4.81 \times 10^{22} & \mathrm{H}_{2} \mathrm{O} & 9.21 \times 10^{22} \\
\mathrm{Fe}_{3} & 9.63 \times 10^{22} & \mathrm{CO}_{2} & 2.07 \times 10^{21} \\
& \mathrm{H}_{2} & 4.14 \times 10^{21} \\
& \mathrm{C} & 4.61 \times 10^{22} \\
& \mathrm{R} & 1.44 \times 10^{23}
\end{array}
$$


The amount of methane required, $4.81 \times 10^{22}$ moles, would occupy an STP volume of $1.08 \times 10^{12} \mathrm{~km}^{3}$, approximately that of the present earth. If this amount had originally existed as an atmosphere, it would have exerted a surface pressure of about $140 \mathrm{~b}$. and would have been about $300 \mathrm{~km}$. deep (scale height $15 \mathrm{~km}$.). These values are probably excessive and suggest that any original methane was probably produced gradually or existed originally in the primordial earth.

Some simple calculations will show that this required methane could have been easily contained within a primordial earth as either free gas or organic compounds which could yield methane on heating. For discussion, we can postulate a primordial earth accreted out of material similar to the carbonaceous chondrites, although the chemical composition is not critical to the discussion. A body of the same mass as the present earth, with a density of $2.5 \mathrm{gm} . / \mathrm{cm}^{3}$, would have a radius, $R_{0}=8300 \mathrm{~km}$. and a volume, $v_{0}=2.39 \times 10^{12} \mathrm{~km} .^{3}$. The required methane, $7.72 \times 10^{23} \mathrm{gm}$, would be less than 0.00015 of the mass of this body. For a primordial earth with a mean porosity of 1 per cent in its upper part, a surface pressure of 1 b., a uniform pressure gradient, and a constant original temperature of $298^{\circ} \mathrm{K}$, the volume necessary to contain the required methane can be derived.

At a depth of $\underline{\mathrm{h}} \mathrm{km}$. from the surface, the lithostatic pressure in bars is equal to $\rho g h=250 \mathrm{~h}$, and the average pressure from the surface to a depth $\underline{h}$, is $\bar{P}=125 \mathrm{~h}$. If Boyle's Law applies to the gas, then $V_{h}$, the volume of rock required to contain the gas, can be calculated from the relationship:

$$
\mathrm{V}_{\mathrm{STP}}=0.01 \overline{\mathrm{P}} \mathrm{V}_{\mathrm{h}}=1.08 \times 10^{12} \mathrm{~km} .^{3}
$$




$$
V_{h}=0.8 \frac{V_{S T P}}{h}=8.64 \times 10^{11} h^{-1}
$$

For a shell from the surface to a depth $h$,

$$
v_{h}=v_{0}-4 / 3 \pi\left(R_{0}-h\right)^{3}
$$

Solution of the equations indicates that a shell about $35 \mathrm{~km}$. thick would contain all required methane. The gas could be contained at a larger depth in a correspondingly smaller volume. The exact results are uncertain because of the numerous assumptions, but it appears that a primordial earth of any reasonable composition might be expected to contain sufficient methane for production of the "excess volatiles" by the mechanism suggested.

It is not unreasonable to assume that the material in the upper region of the primordial earth contained at least 1 per cent by weight of magnetite; such a condition is met by many terrestrial rocks of widely varying chemical composition and al so by the carbonaceous chondrites (Mason, 1958). For such material, each $\mathrm{km} .^{3}$ of rock contains $5.18 \times 10^{13}$ moles of magnetite and $4.30 \times 10^{11} \mathrm{~km} .^{3}$ of rock will supply the magnetite needed for complete reaction. This volume of rock corresponds to a sphere of radius $4680 \mathrm{~km}$, or to a shell from the surface of the present earth to a depth of $990 \mathrm{~km}$. (the corresponding thickness for the primordial earth postulated above would be about $550 \mathrm{~km}$. ).

It is not necessary to suggest that reaction actually occurred at such great depths if some method of convection operated to bring fresh material to shallower levels. For example, if reaction can occur to a depth of only $1 \mathrm{~km}$., a total of 850 overturn cycles would be needed to supply the required magnetite. The number of cycles required decreases approximately linearly as 
the thickness of the reacting layer is increased; thus, a 20-km. layer requires about 40 renewals, and a $100-\mathrm{km}$. shell only 9 . If such convection takes place at rates estimated for the present earth (about $1 \mathrm{~cm} . / \mathrm{yr}$; Orowan, 1964), material could move to the surface from a depth of $1000 \mathrm{~km}$. in about $10^{8}$ years. The operation of such a mechanism would not change the total amount ot magnetite required, but would allow reaction to be restricted to a narrow zone closer to the surface.

The amount of hydrogen produced by complete reaction, $4.14 \times 10^{21}$ moles or $8.34 \times 10^{21}$ grams, would exert a maximum surface pressure of about $1.5 \mathrm{~b}$. However, loss of hydrogen into space would tend to keep $\mathrm{P}_{\mathrm{H}_{2}}$ at a lower value (Hol 1 and, 1962).

The total $\mathrm{CO}_{2}$ produced, $2.07 \times 10^{21}$ moles, would have exerted a surface pressure of about 17 b. Precipitation of carbonate sediments would probably have occurred long before such a high value was reached (Rubey, 1951) and it is questionable whether 1 ife could have originated and survived under such a high $\infty_{2}$ pressure. These results suggest a gradual evolution of $\infty_{2}$ into the atmosphere (Rubey, 1951 ).

Disposal of the hypothetical solid products is not difficult. The graphite produced, $4.61 \times 10^{22}$ moles, would form a sphere about $390 \mathrm{~km}$. in radius, or a layer on the surface of the earth about $0.5 \mathrm{~km}$. thick. However, if it constituted 1 per cent of the upper part of the earth, it could be dispersed in a layer $50 \mathrm{~km}$. thick. If the reduced phase, $R$, is considered as iron, a volume of $1.03 \times 10^{9} \mathrm{~km} \cdot{ }^{3}$ is produced, corresponding to a sphere about $625 \mathrm{~km}$. in radius or to 1 per cent of the earth to a depth of about $200 \mathrm{~km}$. If temperatures above the melting point of iron are reached, the metal could segregate toward the center. Other reduced phases which could 
develop would have slightly larger volumes, but could still be distributed as small percentages of the material in the upper part of the earth.

Despite the oversimplified assumptions of this model and the uncertainties in the calculations, it does appear that all the "excess volatile" water and $\infty_{2}$ now present could have originated from reaction of original methane with accessory minerals at moderate depths within the earth. Such a model has two significant advantages. First, no rigorous assumptions are needed as to the original mineralogy and composition of the earth; the reactions involve only small amounts of accessory minerals, and gross mineralogical characteristics are unaffected. Second, there is no necessity for equilibrium between the atmosphere and the surface rock at any time.

The high calculated surface pressure for original methane, about $140 \mathrm{~b}$., suggests that it did not form an atmosphere prior to reaction. The required methane could have been contained within the upper levels of the earth, although, if temperatures above $1000^{\circ} \mathrm{C}$ existed in this region soon after accretion (MacDonald, 1959), methane would not remain in equilibrium with magnetite-graphite assemblages, and conversion to water and $\mathrm{CO}_{2}$ would have proceeded rapidly. The product $\mathrm{CO}_{2}$ would al so have exerted an unreasonably high surface pressure, suggesting that it was evolved gradually until formation of carbonate-bearing sediments could occur (Rubey, 1951).

This mechanism is in general agreement with models of atmosphere development proposed earlier (Rubey, 1951; Holland, 1962). However, consideration of possible heterogeneous reactions at depth removes the necessity for an original methane-rich atmosphere. The model leads directly to an atmosphere enriched in water, $\mathrm{CO}_{2}$, and $\mathrm{N}_{2}$ which resembles the second stage of Holland's 
(1962) model or the original atmosphere proposed by Rubey (1951). 3

The materials-balance method used here gives no indication of the time required to produce the water and $\mathrm{CO}_{2}$ or of whether the rate of production has been constant throughout geologic time. Rubey (1951, p. 1138) has pointed out that the present rate of introduction of volatiles to the surface could product the required amounts during geologic time. There is thus no reason to require large production of volatiles early in the earth's history, but the mechanism described would be consistent with either model.

If temperatures in the atmosphere are too low for establishment of equilibrium, further compositional changes will depend largely on the initiation of photosynthesis to produce the present oxygenated atmosphere. The date for the origin of $\mathrm{life}$ and the magnitude of photosynthetic effects are uncertain; the discovery of apparently photosynthetic algae in Precambrian rocks (Rutten, 1962; Barghoorn and Tyler, 1965) indicates that photosynthesis was operative, at least locally, as much as $2 \times 10^{9}$ years ago, a result which must be included in any consideration of the evolution of the atmosphere. (Cloud, 1965).

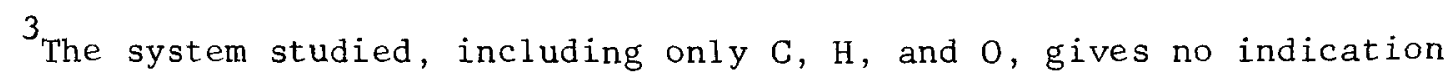
of the behavior of $\mathrm{N}_{2}$ during oxidation of the methane. Higher values of $\mathrm{P}_{2}$ promote the decomposition of $\mathrm{NH}_{3}$ to $\mathrm{N}_{2}$ and $\mathrm{H}_{2}$, and it is probable that such reaction, occurring in parallel with the oxidation of methane, could produce the observed $\mathrm{N}_{2}$ in the atmosphere. The amount of "excess volatile" $\mathrm{N}_{2}$ (Rubey, 1951, p. 1116) is $4.2 \times 10^{21} \mathrm{gm}$. or $1.5 \times 10^{20}$ moles, about 0.002 of the amount of water and $\mathrm{CO}_{2}$ required. 
GENERAL OONCLUSIONS

(1) The study of equilibrium between the mineral graphite and a coexisting gas phase in the system $\mathrm{C}-\mathrm{H}-\mathrm{O}$ is of extreme significance in estimating conditions of formation of graphite-bearing mineral assemblages which occur in metamorphosed sediments, in certain igneous rocks, and in several classes of iron and stony meteorites. Ideally, the system graphite + gas is trivariant; in the present study, values of $T, \mathrm{P}_{\text {gas }}$, and $\mathrm{E}_{\mathrm{O}_{2}}$ are independently specified. Values of $\mathrm{P}_{\mathrm{CO}_{2}}, \mathrm{P}_{\mathrm{CO}}, \mathrm{P}_{\mathrm{H}_{2} \mathrm{O}}, \mathrm{P}_{\mathrm{H}_{2}}$, and $\mathrm{P}_{\mathrm{CH}_{4}}$ in the coexisting gas phase are then explicitly calculated with a high-speed computer. The numerical results support some general conclusions about the composition of the gas phase in equilibrium with graphite-bearing assemblages over a range of temperatures and gas pressures attainable in geological environments.

(2) The contribution of methane, $\mathrm{CH}_{4}$, to the gas phase in equilibrium with graphite-bearing assemblages is significant over a wide range of geologically realizable conditions. In a moderately reduced gas phase, methane may constitute 30 to 50 per cent of the total gas pressure, with the excess composed chiefly of water and $\mathrm{O}_{2}$. Under conditions of even lower $\mathrm{P}_{\mathrm{O}_{2}}$, the gas phase may be almost entirely methane. The existence of significant amounts of methane in the gas phase is indicated by the presence of minerals stable at low $\mathrm{P}_{\mathrm{O}_{2}}$, such as fayalite, wistite, and native iron.

(3) Graphite in a sediment will act to produce increasingly reduced mineral assemblages during rising temperatures associated with progressive metamorphism. Such a mechanism may explain the commonly observed reduction of original sediments with increasing metamorphic grade in both regional and contact-metamorphic environments. In particular, the existence of graphite 
or equivalent organic matter will reduce original hematite to magnetite at very low temperatures.

(4) Because of the low gram-molecular weight of graphite, trace amounts will be sufficient to act as an effective internal oxygen buffer in systems as small as individual rock layers. Observed differences in $\mathrm{P}_{\mathrm{O}_{2}}$ in metamorphic rocks over short distances may be conditioned by the presence or absence of graphite in the assemblage; a definite distinction between the two cases is necessary for a detailed study of such rocks.

(5) The equilibrium relations suggest a model for the development and evolution of the earth's atmosphere in which original methane is oxidized to water and $\mathrm{OO}_{2}$ by reaction with trace amounts of graphite and ferrousferric minerals such as magnetite in the upper part of the primordial earth. Even for maximum required water and $\mathrm{CO}_{2}$, the materials needed are not excessive and could reasonably have been contained within a variety of possible primordial earths. Such a mechanism is independent of the gross composition and mineralogy of the earth and does not require high surface temperatures or establishment of equilibrium between atmosphere and surface. The reactions can therefore be applied to a wide range of proposed origins for the earth, its atmosphere, and its oceans. Possible reaction products are graphite, hydrogen, and iron, all of which could be incorporated into the primordial earth without difficulty. The time required for completion of the process is indeterminate, although the calculated high surface pressures of both reactant methane and product $\mathrm{CO}_{2}$ favor the interpretation that a relatively long period of time was involved (Rubey, 1951; Holland, 1962). However, the process could have been completed early in the precambrian before most of the available sedimentary record originated. 
In summary, graphite is a common and widespread accessory mineral in both terrestrial and extraterrestrial rocks. It is of particular importance because of its relationship to the composition of a coexisting gas phase in the system $\mathrm{C}-\mathrm{H}-\mathrm{O}$. The presence of graphite in a mineral assemblage thus provides an additional constraint on the conditions of temperature, pressure, and composition in which the assemblage formed. Furthermore, changes in composition of the coexisting gas phase in response to changes in temperature have considerable significance for studies of progressive metamorphism and for speculations about the origin and development of the terrestrial atmosphere. For these reasons, the detection and identification of even trace amounts of graphite in a mineral assemblage are of particular importance to petrologic studies. 


\section{ACKNOWLEDGEMENTS}

The studies were carried out while the writer was supported by a National Academy of Sciences - National Research Council Postdoctoral Resident Research Asscilateship at the Goddard Space Flight Center, National Aeronautics and Space Administration, Greenbelt, Maryland. I am very grateful to Mr. Arthur Smith, of the Theoretical Division, Goddard Space Flight Center, for developing the necessary FORTRAN IV computer programs and for assisting with the data tabulation. Although the writer alone is responsible for the conclusions presented, he is indebted to H. P. Eugster, H. J. Greenwood, and W. M. Mel son for many useful suggestions; George Skippen, of Johns Hopkins

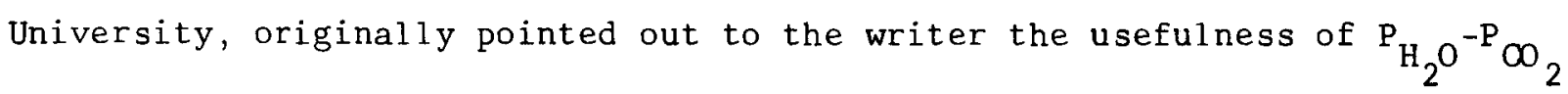
isotherms and their significance in progressive metamorphism. 
Allen, C. W., Astrophysical quantities, 2nd ed., Athlone Press, London, 291 PP., 1963.

Anders, E., Origin, age, and composition of meteorites, Space Sci. Revs., $\underline{3}$, $583-714,1964$.

Andersen, C. A., K. Keil, and B. Mason, Silicon oxynitride: a meteoritic mineral, Science, $146,256-257,1964$.

Anderson, G. M.; The calculated fugacity of water to $1000^{\circ} \mathrm{C}$ and 10,000 bars, Geochim. et Cosmochim. Acta, 28, 713-715, 1964.

Barghoorn, E. S. and S. A. Tyler, Microorganisms from the Gunflint chert, Science, $147,563-577,1965$.

Brancazio, P. J. and A. G. W. Cameron, The origin and evolution of atmospheres and oceans, John Wiley and Sons, New York, 314 pp., 1964.

Buddington, A. F. and D. H. Lindsley, Iron-titanium oxide minerals and synthetic equivalents, J. Petrol., 5, 310-357, 1964.

Bundy, F. P., H. P. Bovenkerk, H. M. Strong, and R. H. Wentorf, Jr., Diamond-graphite equilibrium 1 ine from growth and graphitization of diamond, J. Chem. Phys., 35, 383-391, 1961 .

Chinner, G. A., Pelitic gneisses with varying ferrous/ferric ratios from Glen Clova, Angus, Scotland, I. Petrol., 1, 178-217, 1960.

Cloud, P. E., Jr., Significance of the Gunflint (Precambrian) microflora, Science, 148, 27-35, 1965 .

Dayhoff, M. O., E. R. Lippincott, and R. V. Eck, Thermodynamic equilibria in prebiological atmospheres, Science, 146, 1461-1464, 1964. Denbigh, K., The principles of chemical equilibrium, Cambridge University Press, Cambridge, 491 pp., 1957. 
Donn, W. L., B. D. Donn, and W. G. Valentine, on the early history of the earth, Bull $\cdot$ Geol. Soc. Amer. , 76, 287-306, 1965.

Douslin, D. R., R. H. Harrison, R. T. Moore, and J. P. McCuliogh, P-V-T relations for methane, J. Chem. Eng. Data, 9, 358-363, 1964 .

Duke, M. B., Metallic iron in basaltic achondrites, J. Geophys. Res., 70, $1523-1527,1965$

Elinson, M. M. and V. S. Polykovski, The composition of gases in pneumatolytichydrothermal solutions, Geochemistry (USSR) (English transl.), no. 8, $799-807,1963 a$.

Elinson, M. M. and V. S. Polykovskii, Some characteristics of the process of formation of quartz crystal pegmatites as revealed by an investigation of gas inclusions in minerals and rocks, Geochemistry (USSR) (English trans1.), no. $10,977-987,1963 \mathrm{~b}$.

Eugster, H. P., Reduction and oxidation in metamorphism, in Researches in Geochemistry, edited by P. H. Abelson, pp. 397-426, John Wiley and Sons, New York, 1959.

Eugster, H. P. and D. R. Wones, Stability relations of the ferruginous biotite, annite, $\underline{\mathrm{J}} \cdot \underline{\text { Petrol }}, \underline{3}, 82-125,1962$.

French, B. M., Graphitization of organic matter in a progressively metamorphosed Precambrian iron formation, Science, 146, 917-918, 1964.

French, B. M., Progressive contact metamorphism of the Biwabik iron-formation, Mesabi Range, Minnesota, Minn. Geol. Surv. Bul1. 45, 1965, in press.

French, B. M. and H. P. Eugster, Experimental control of oxygen fugacities by graphite-gas equilibriums, J. Geophys. Res., 70, 1529-1539, 1965. Gundersen, J. N. and G.: M. Schwartz, The geology of the metamorphosed Biwabik iron-formation, Eastern Mesabi District, Minnesota, Minn. Geol. Surv. Bu11., 43, 139 Pp., 1962. 
Hoering, T. C. and R. Hart, A geochemical study of some Adirondack graphites, Carnegie Institution of Washington Year Book 63, 265-267, 1964.

Holland, H. D., Model for the evolution of the earth's atmosphere, in

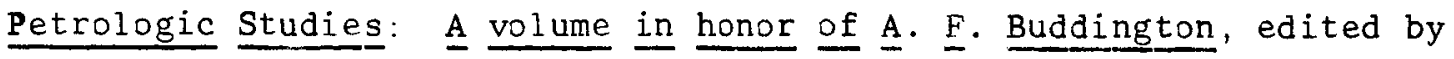
A. E. J. Engel, H. L. James, and B. F. Leonard, Pp. 447-477, Geological Society of America, New York, 1962.

Holland, H. D., On the chemical evolution of the terrestrial and Cytherean atmospheres, in The origin and evolution of atmospheres and oceans, edited by P. J. Brancazio and A. G. W. Cameron, PP. 86-101, John Wiley and Sons, New York, 1964.

JANAF (Joint Army, Navy, Air Force) tables, Joint Army, Navy, Air Force tables of thermochemical data, compiled by Dow Chemical Company, Thermal Laboratory, Midland, Michigan, 1960 and later.

Keil, K. and C. A. Andersen, Electron microprobe study of the Jajh deh Kot Lalu enstatite chondrite, Geochim. et Cosmochim. Acta, 29, 621-632, 1965.

Kennedy, G. C., Pressure-volume-temperature relations in $\mathrm{CO}_{2}$ at elevated temperatures and pressures, Am. J. Sci., 252, 225-241, 1954.

Korzhinskii, D. S., Physicochemical basis of the analysis of the paragenesis of minerals, Consultants Bureau, New York, 142 pp., 1959 (translated from the Russian).

Kranck, S. H., A study of phase equilibria in a metamorphic iron formation, J. Petrol., 2, $137-184,1961$.

Krauskopf, K. B., The use of equilibrium calculations in finding the composition of a magmatic gas phase, in Researches in Geochemistry, edited by P. H. Abelson, pp. 260-278, John Wiley and Sons, New York, 1959. 


\section{REFERENCES (48)}

Krinov, E. L., Principles of meteoritics, Pergamon Press, New York, 535 pp., 1960 (translated from the Russian).

LaBerge, G. L., Development of magnetite in iron-formations of the Lake Superior region, Econ. Geol., 59, 1313-1342, 1964.

Lepp, H. and S. S. Goldich, Origin of Precambrian iron formations, Econ. Geo1., 59, 1025-1060, 1964.

MacDonald, G. J. F., Calculations on the thermal history of the earth, J. Geophys. Res., 64, 1967-2000, 1959.

Malinin, S. D., The system water - carbon dioxide at high temperatures and pressures, Geochemistry (USSR) (English transl.) no. 3, p. 292-306, 1959.

Mason, B., Meteorites, John Wiley and Sons, New York, 274 pp., 1962.

Melson, W. G. and G. Switzer, Plagioclase-spinel-graphite xenoliths in metallic iron-bearing basalts, Disko Island, Greenland (abstract), paper presented at Canadian Mineralogical Society Meeting, March, 1965.

Miller, S. L. and H. C. Urey, Organic compound synthesis on the primitive earth, Science, $130,245-251,1959$.

Miyashiro, A., Oxidation and reduction in the Earth's crust with special reference to the role of graphite, Geochim. et Cosmochim. Acta, 28, $717-729,1964$.

Mueller, R. F., Phase equilibria and the crystallization of chondritic meteorites, Geochim. et Cosmochim. Acta, 28, 189-207, 1964.

Newton, R. H., Activity coefficients of gases, Ind. Eng. Chem., 27, 302-306, 1935.

Olsen, E., Equilibrium calculations in the system $\mathrm{Mg}, \mathrm{Fe}, \mathrm{Si}, \mathrm{O}, \mathrm{H}$, and $\mathrm{Ni}$, Am. J. Sci. , 261, 943-956, 1963 . 
Oparin, A. I., The origin of life, revised ed., Dover Publications, New York, 270 p., 1957.

Orowan, E., Continental drift and the origin of mountains, Science, 146, $1003-1010,1964$.

Petersil'ye, I. A., S. V. Ikorskii, L. I. Smirnova, A. M. Romanikhin, and E. B. Proskuryakova, Application of gas logging to the investigation of natural gases and bitumens in the Khibina intrusive massif, Geochemistry (USSR) (English transl.), no. $10,945-962,1961$.

Quinn, A. W. and H. D. Glass, Rank of coal and metamorphic grade of rocks of the Narragansett basin of Rhode Island, Econ. Geol., 53, 563-576, 1958.

Ramdohr, P., The opaque minerals in stony meteorites, J. Geophys. Res., 68 , $2011-2036,1963$.

Rankama, K., Geologic evidence of chemical composition of the Precambrian atmosphere, in The Crust of the Earth, edited by A. Poldervaart, Pp. 651-664, Geol. Soc. Amer. Spec. Papers, 62, 1955.

Ringwood, A. E., Chemical and genetic relationships among meteorites, Geochim. et Cosmochim. Acta. , 24, 159-197, 1961 .

Robie, R. A., Thermodynamic properties of minerals, $\underline{U} \cdot \underline{S} \cdot \underline{\text { Geol }}$. Survey, Open-file Rept. TEI-816, 31 p., 1962.

Rubey, W. W., Geologic history of sea water: an attempt to state the problem, Bull. Geol. Soc. Am., 62, 1111-1148, 1951.

Rutten, M. G., The geological aspects of the origin of life on earth, Elsevier Publishing Co., New York, 146 p., 1962.

Shaw, D. M., Geochemistry of pelitic rocks. Part III: Major elements and general geochemistry, Bul1. Geol. Soc. Am., 67, 919-934, 1956. 
Shaw, H. R. and D. R. Wones, Fugacity coefficients for hydrogen gas between $0^{\circ}$ and $1000^{\circ} \mathrm{C}$, for pressures to $3000 \mathrm{~atm} ., \underline{A m} \cdot \underline{\mathrm{J}} \cdot \underline{\text { Sci. }} . \underline{262}$, $918-929,1964$.

Suess, H. E., Thermodynamic data on the formation of solid carbon and organic compounds in primitive planetary atmospheres, I. Geophys. Res., 67, 2029-2034, 1962.

Takenouchi, S. and G. C. Kennedy, The binary system $\mathrm{H}_{2} \mathrm{O}-\mathrm{O}_{2}$ at high temperatures and pressures, Am. J. Sci., 262, 1055-1074, 1964.

Thompson, J. B. Jr., The thermodynamic basis for the mineral facies concept, Am. I. Sci $\cdot$, 253, 65-103, 1955 .

Todheide, K. and E. U. Franck, Das Zwischenphasengebiet und die kritische Kurve im System Kohlendioxid-Wasser dis zu Drucken von 3500 bar, $\underline{\mathbf{z}}$. Physik. Chem., Neue Folge, 37, 387-401, 1963.

Turner, F. J. and J. Verhoogen, Igneous and Metamorphic Petrology, 2nd ed., New York, McGraw-Hill Book Co., Inc., 694 p., 1960.

Urey, H. C., The planets, their origin and development, Yale University Press, New Haven, 245 pp., 1952.

Vdovykin, G. P., Carbonaceous matter in meteorites and its origin, Geochemistry International, No. 2, p. 256-261, 1964.

Wagman, D. D., J. E. Kilpatrick, W. J. Taylor, K. S. Pitzer, and F. D. Rossini, Heats, free energies, and equilibrium constants of reactions involving $\mathrm{O}_{2}, \mathrm{H}_{2}, \mathrm{H}_{2} \mathrm{O}, \mathrm{C}, \mathrm{CO}, \mathrm{CO}_{2}$, and $\mathrm{CH}_{4}, \underline{\mathrm{J}} \cdot \underline{\text { Res., }}$ NBS $\underline{34}, 143-162$, 1945.

Walenta, K., Naturliches Eisen(II)-Oxyd (Wustit) aus der vulkanischen Tuffbreccie von Scharnhausen bei Stuttgart, Neues Jahrb. Mineral., Monatsh., 150-159, 1960. 


\section{REFERENCES (51)}

Wasserburg, G. J., G. J. F. MacDonald, F. Hoyle, and W. A. Fowler, Relative contributions of uranium, thorium, and potassium to the heat piduction of the earth, Science, 143, 465-467, 1964.

Wood, J. A., Metamorphism in chondrites, Geochim. et Cosmochim. Acta, 26, $739-749,1962$.

Wood, J. A., On the origin of chondrules and chondrites, Icarus, $\underline{2}$, $152-180,1963$.

Yoder, H. S. Jr., Role of water in metamorphism, in The Crust of the Earth, edited by A. Poldervaart, Pp. 505-523, Geol. Soc. Am. Spec. Papers, 62, 1955 .

Zen, E., Components, phases and criteria of chemical equilibrium in rocks, Am. J. Sci. , 261, 929-942, 1963 . 


\section{FIGURE CAPTIONS}

1. Calculated composition of a gas phase in equilibrium with graphite as a function of $\mathrm{f}_{\mathrm{O}_{2}}$ for a temperature of $327^{\circ} \mathrm{C}\left(600^{\circ} \mathrm{K}\right)$ and total gas pressures of 1 bar, 1000 bars, and 10 kilobars. Values of $\log _{10} P_{i}$ for $\infty_{2}, \infty, \mathrm{H}_{2} \mathrm{O}, \mathrm{H}_{2}$, and $\mathrm{CH}_{4}$ are plotted against $\log _{10} \mathrm{f}_{\mathrm{O}_{2}}$; dashed extensions of the curves indicate impossible values for which $\mathrm{P}_{\infty_{2}}+\mathrm{P}_{\infty}>\mathrm{P}_{\text {gas }}$. Vertical 1 ines above the curves indicate $\mathrm{f}_{\mathrm{O}_{2}}$ values for solid-phase oxygen buffers.

2. Calculated composition of a gas phase in equilibrium with graphite as a function of $\mathrm{f}_{\mathrm{O}_{2}}$ for a temperature of $627^{\circ} \mathrm{C}\left(900^{\circ} \mathrm{K}\right)$ and total gas pressures of 1 bar, 1000 bars, and 10 kilobars. Values of $\log _{10} P_{i}$ for $\infty_{2}, \infty$, $\mathrm{H}_{2} \mathrm{O}, \mathrm{H}_{2}$, and $\mathrm{CH}_{4}$ are plotted against $\log _{10} \mathrm{f}_{\mathrm{O}_{2}}$; dashed extensions of the curves indicate impossible values for which $\mathrm{P}_{\mathrm{O}_{2}}+\mathrm{P}_{\infty}>\mathrm{P}_{\text {gas }}$. Vertical lines above the curves indicate $\mathrm{f}_{2}$ values for solid-phase oxygen buffers.

3. Calculated composition of a gas phase in equilibrium with graphite as a function of $\mathrm{f}_{2}$ for a temperature of $927^{\circ} \mathrm{C}\left(1200^{\circ} \mathrm{K}\right)$ and total gas pressures of 1 bar, 1000 bars, and 10 kilobars. Values of $\log _{10} p_{i}$ for $\infty_{2}, \infty$, $\mathrm{H}_{2} \mathrm{O}, \mathrm{H}_{2}$ and $\mathrm{CH}_{4}$ are plotted against $\log _{10} \mathrm{f}_{\mathrm{O}_{2}}$; dashed extensions of the curves indicate impossible values for which $\mathrm{P}_{\infty_{2}}+\mathrm{P}_{\infty}>\mathrm{P}_{\text {gas }}$. Vertical 1 ines above the curves indicate $\mathrm{f}_{2}$ values for solid-phase oxygen buffers. 
4. Calculated composition of a gas phase in equilibrium with graphite as a function of temperature for $\mathrm{f}_{\mathrm{O}_{2}}$ values specified by the quartz-fayalite-magnetite buffer. Total gas pressure equals 1000 bars (left) and 10 kilobars (right). Values of $\log _{10} P_{i}$ for $\infty_{2}, \infty$, $\mathrm{H}_{2} \mathrm{O}, \mathrm{H}_{2}$, and $\mathrm{CH}_{4}$ are plotted against temperature in the upper part of the diagrams; corresponding values of $\log _{10} \mathrm{f}_{\mathrm{O}_{2}}$ are plotted in the lower part.

5. Calculated composition of a gas phase in equilibrium with graphite as a function of temperature for $\mathrm{f}_{2}$ values specified by the combined magnetite-iron and magnetite-wlstite buffers. Total gas pressure equals 1000 bars. Values of $\log _{10} \mathrm{P}_{\mathrm{i}}$ for $\infty_{2}, \infty, \mathrm{H}_{2} \mathrm{O}, \mathrm{H}_{2}$, and $\mathrm{CH}_{4}$ are plotted against temperature in the upper part of the diagram; corresponding values of $\log _{10} f_{\mathrm{O}_{2}}$ are plotted in the lower part.

6. Calculated composition of a gas phase in equilibrium with graphite as a function of temperature for $\mathrm{f}_{\mathrm{O}_{2}}$ values controlled by the combined magnetite-iron and wllstite-iron buffers. Total gas pressure equals 1000 bars. Values of $\log _{10} P_{i}$ for $\mathrm{CO}_{2}, \infty, \mathrm{H}_{2} \mathrm{O}, \mathrm{H}_{2}$, and $\mathrm{CH}_{4}$ are plotted against temperature in the upper part of the diagram; corresponding $\mathrm{f}_{2}$ values are plotted in the lower part.

7. Calculated mole percentages of methane, $\mathrm{CH}_{4}$, as a function of temperature in a gas phase coexisting with graphite at $\mathrm{f}_{\mathrm{O}_{2}}$ values established by various solid-phase oxygen buffers. Total gas pressure equals 1 bar. 
8. Calculated mole percentages of methane, $\mathrm{CH}_{4}$, as a function of temperature in a gas phase coexisting with graphite at $\mathrm{f}_{\mathrm{O}_{2}}$ values established by various solid-phase oxygen buffers. Total gas pressure equals 1000 bars.

9. Calculated partial pressures of $\mathrm{OO}_{2}, \mathrm{CO}, \mathrm{H}_{2} \mathrm{O}, \mathrm{H}_{2}$ and $\mathrm{CH}_{4}$ as a function of temperature for gas phases coexisting with graphite. Total gas pressure equals 1 bar. The curves correspond to values of $\mathrm{f}_{\mathrm{O}_{2}}$ specified by the quartz-fayalite-magnetite buffer (solid lines) and by the combined magnetite-iron and magnetite-wllstite buffers (dashed 1 ines).

10. Calculated partial pressures of $\mathrm{CO}_{2}, \infty, \mathrm{H}_{2} \mathrm{O}, \mathrm{H}_{2}$, and $\mathrm{CH}_{4}$ as a function of temperature for gas phases coexisting with graphite. Total gas pressure equals 1000 bars. The curves correspond to values of $\mathrm{f}_{\mathrm{O}_{2}}$ specified by the quartz-fayalite-magnetite buffer (solid lines) and by the combined magnetite-iron and magnetite-wistite buffers (dashed lines).

11. Calculated temperature - total gas pressure curves which represent the upper limits of stability of various solid-phase buffer assemblages with graphite and a gas phase. The curves are actually projections of univariant curves along the $\mathrm{f}_{2}$ axis onto the $\mathrm{P}_{\text {gas }}-\mathrm{T}$ plane.

12. Calculated values of $\mathrm{P}_{\mathrm{H}_{2} \mathrm{O}}$ and $\mathrm{P}_{\mathrm{CO}_{2}}$ in a gas phase in equilibrium with graphite at a total gas pressure of 100 bars. At each temperature, permissible compositions 1 ie on curved isotherms (solid lines). Dashed lines indicate estimated compositions for a gas phase in equilibrium with graphite and various solid-phase buffer assemblages. 
13. Calculated values of $\mathrm{P}_{\mathrm{H}_{2} \mathrm{O}}$ and $\mathrm{P}_{\mathrm{OO}_{2}}$ in a gas phase in equilibrium with graphite at a total gas pressure of 1000 bars. At each temperature, permissible compositions 1 ie on curved isotherms (solid lines). Dashed lines indicate estimated compositions for a gas phase in equilibrium with graphite and various solid-phase buffer assemblages.

14. Values of $\mathrm{f}_{2}$ established in a gas phase in equilibrium with graphite as a function of temperature for total gas pressures of 1 bar and 2000 bars. Values for a system in which the H/O ratio of the gas phase is fixed at $2 / 1$ (heavy solid 1 ines), corresponding to progressive metamorphism of a graphite-bearing sediment containing interstitial water, fall close to those calculated for the system C-O (heavy dashed lines) (French and Eugster, 1965). Both sets of curves intersect progressively reduced solid-phase buffers (1ight solid lines) with increasing temperature.

15. Calculated composition of a gas phase in equilibrium with graphite as a function of temperature for a system in which the $\mathrm{H} / \mathrm{O}$ ratio of the gas phase is maintained at $2 / 1$. For temperatures below $1000^{\circ} \mathrm{C}, \mathrm{H}_{2} \mathrm{O}$ dominates, and $\mathrm{CO}_{2}$ and $\mathrm{CH}_{4}$ are present in approximately equal amounts. The $\mathrm{f}_{\mathrm{O}_{2}}-\mathrm{T}$ curve for this system (heavy solid line in lower part of figure) intersects more reduced buffers; with increasing temperature, an original magnetite-quartz-graphite rock should progressively develop fayalite, wllstite, and iron. 

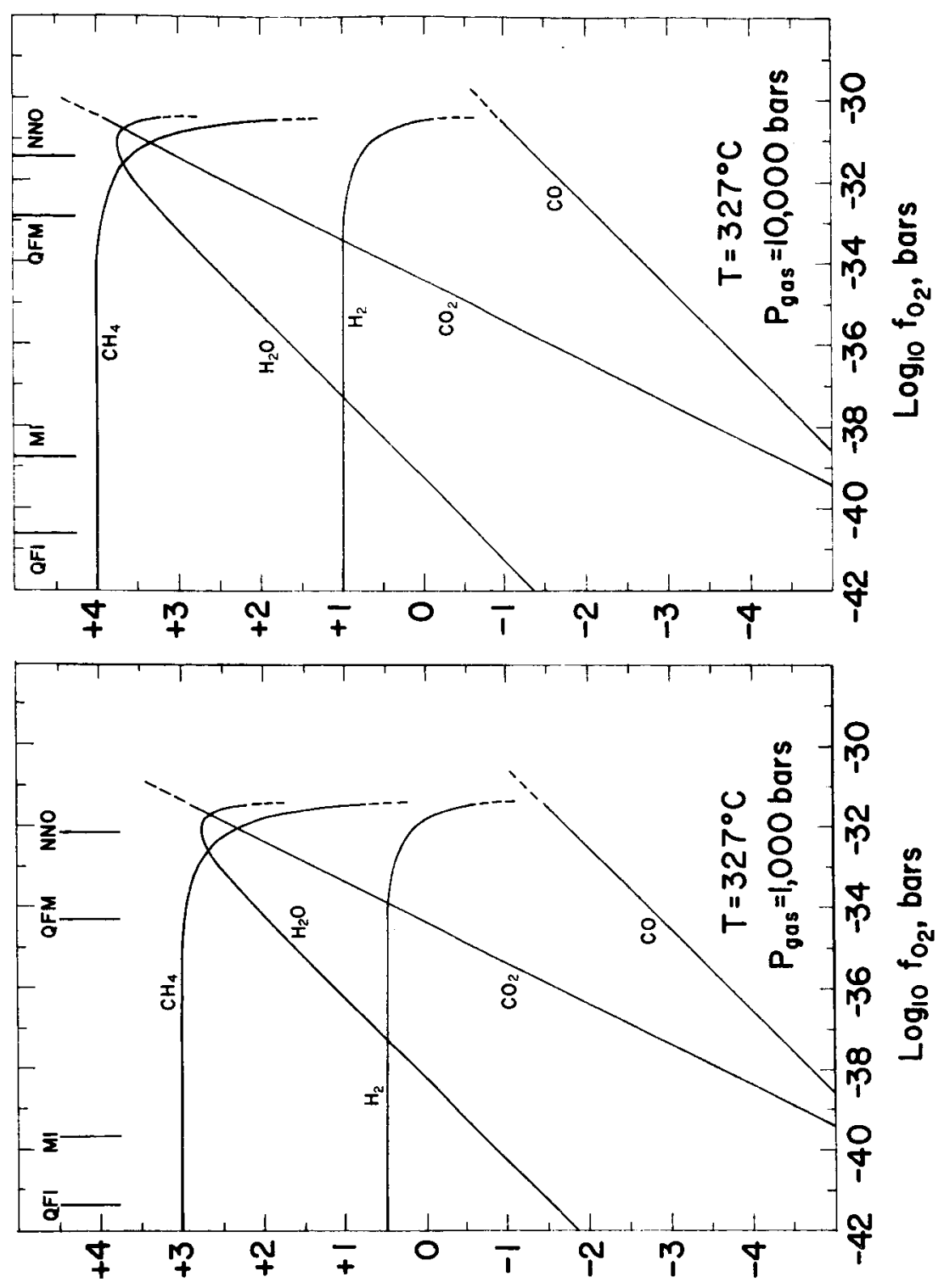

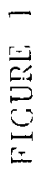

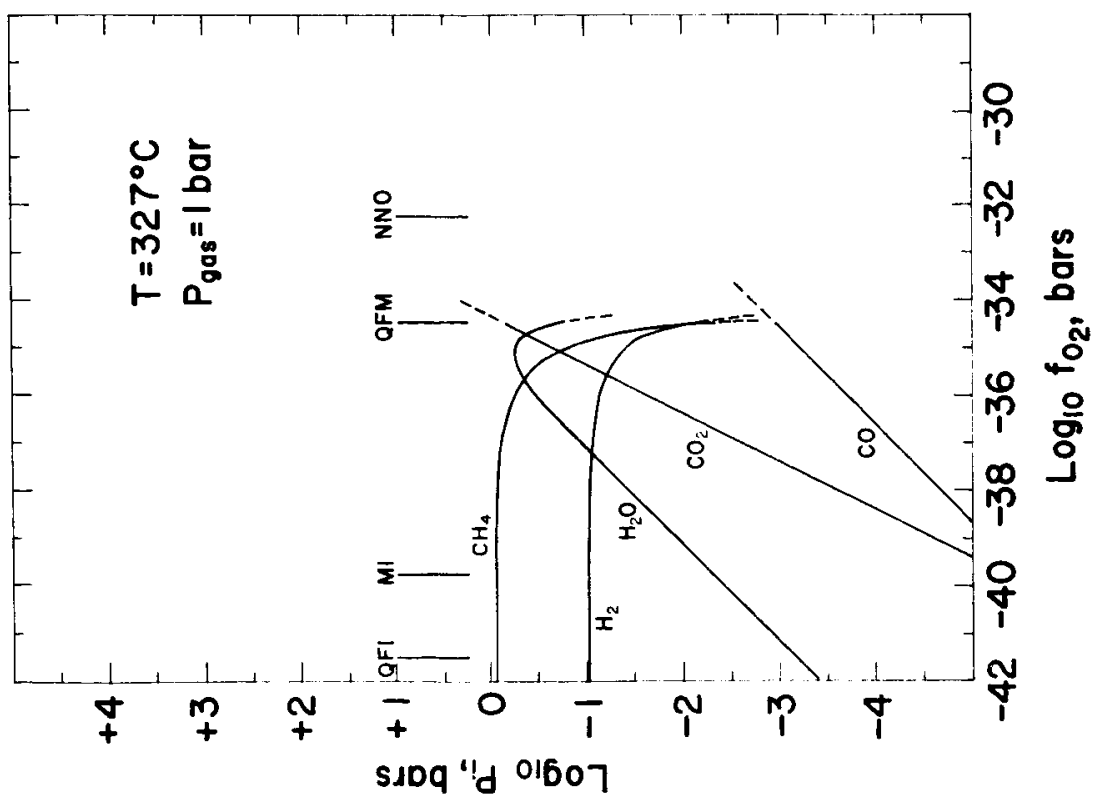



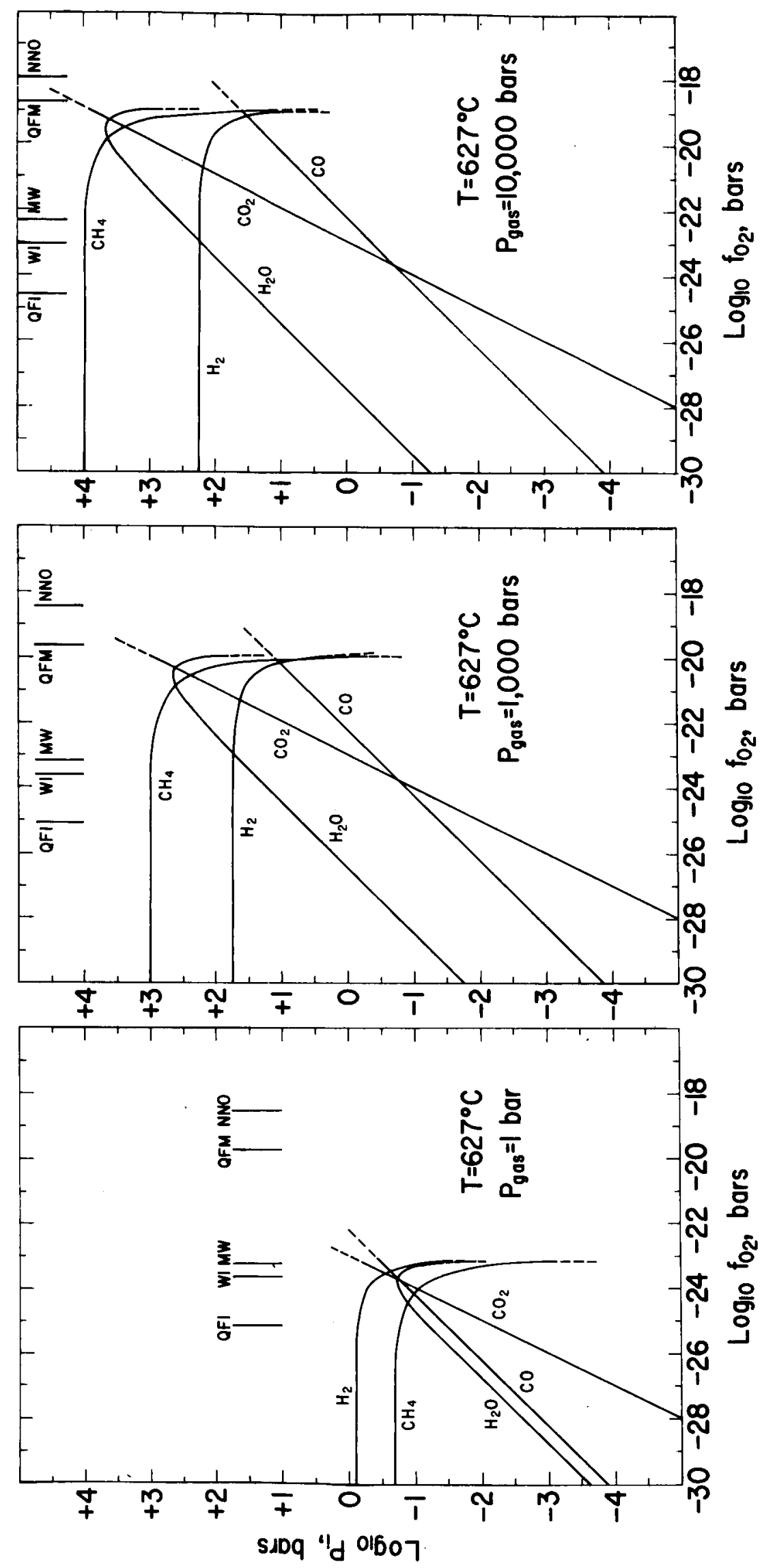

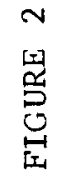



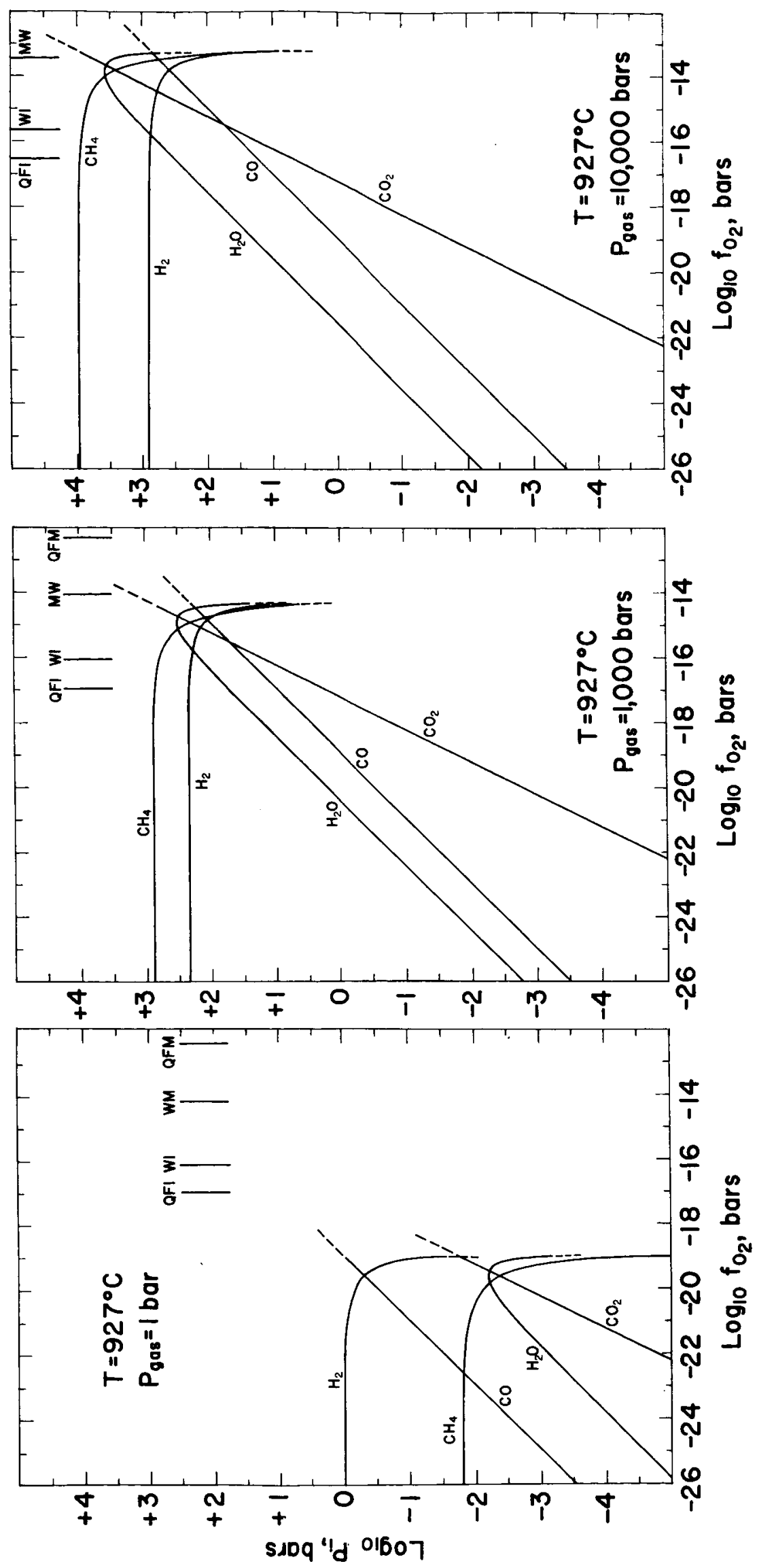

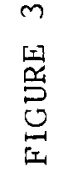



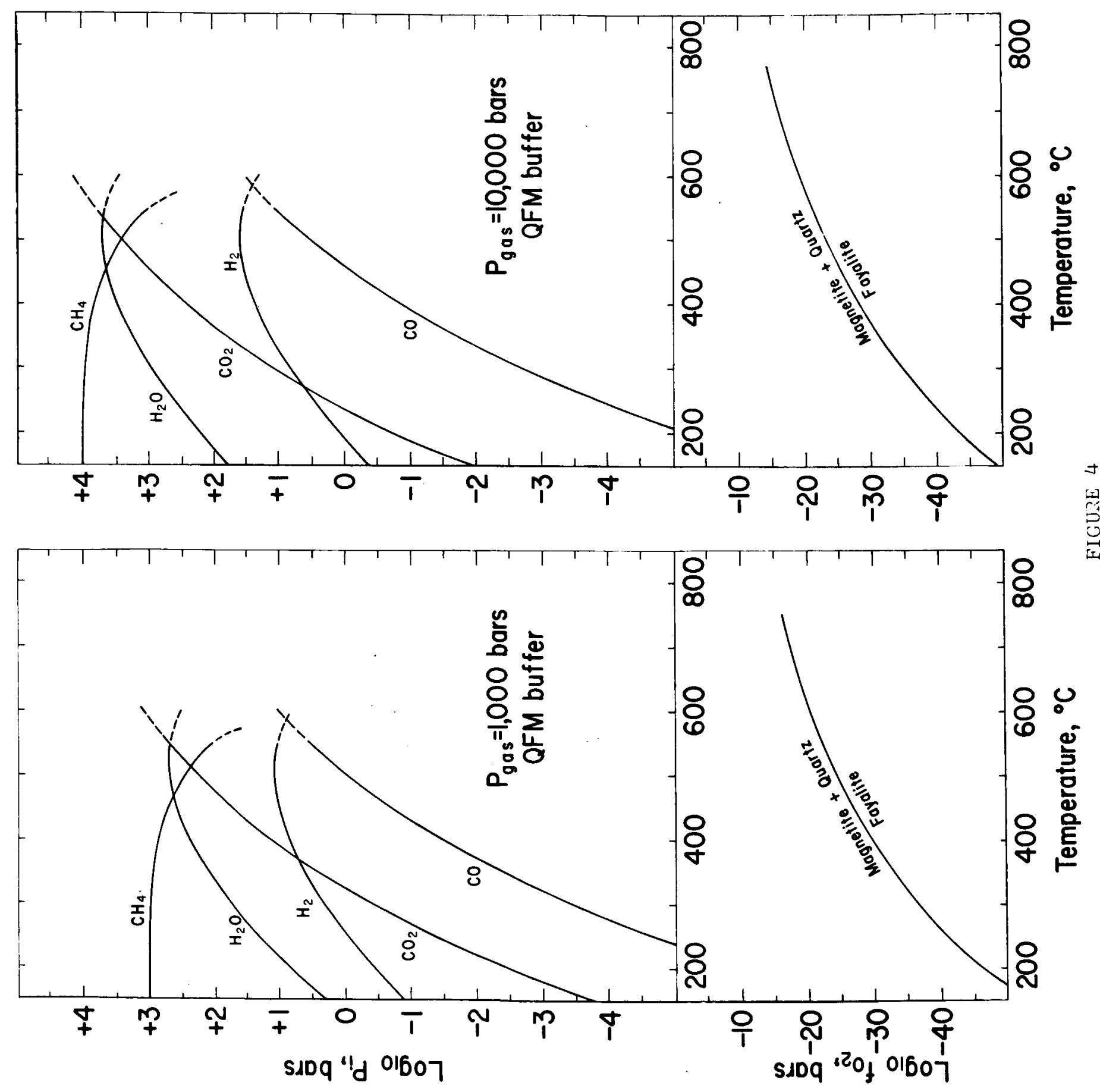


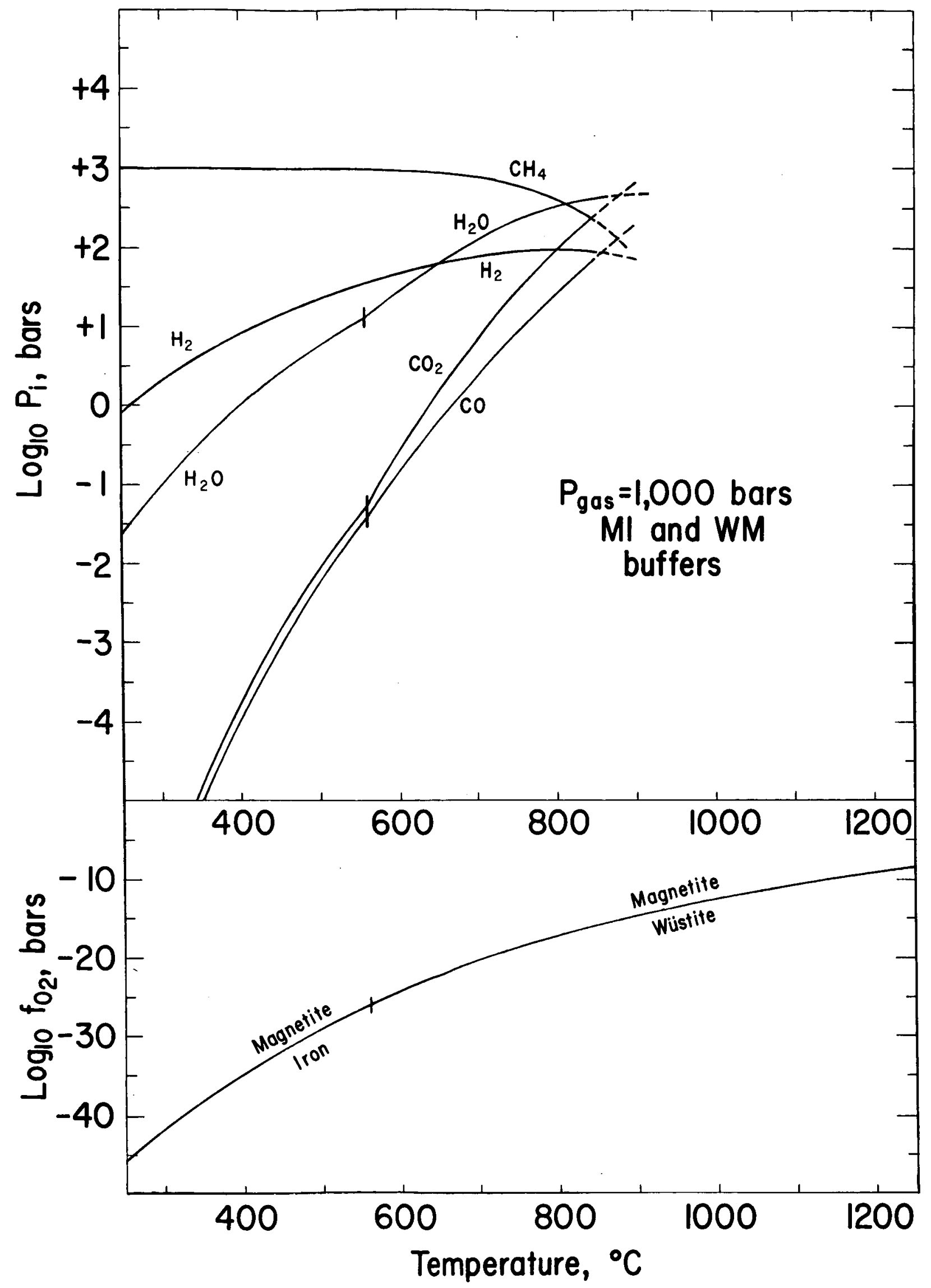

FIGURE 5 


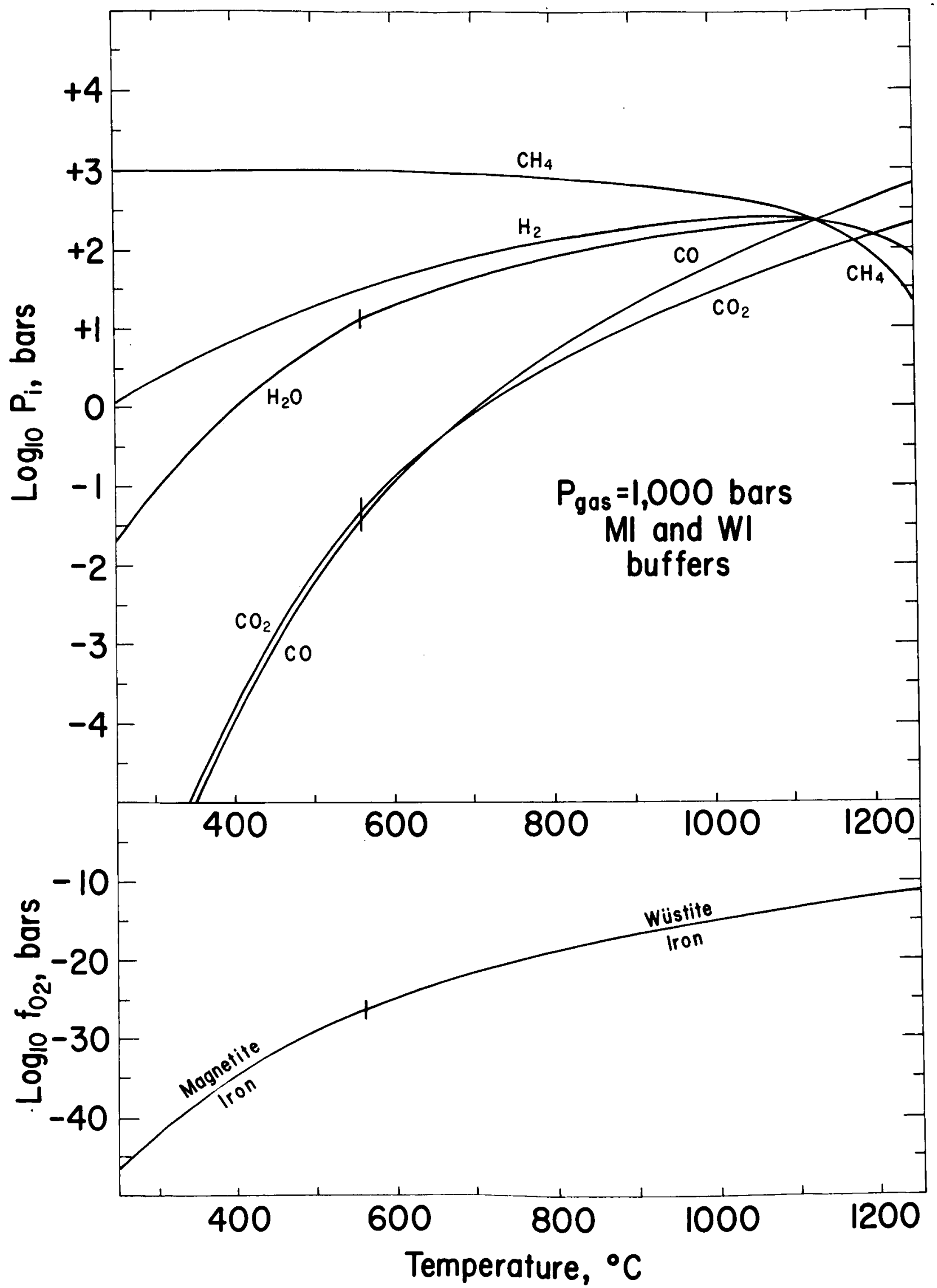

FIGURE 6 


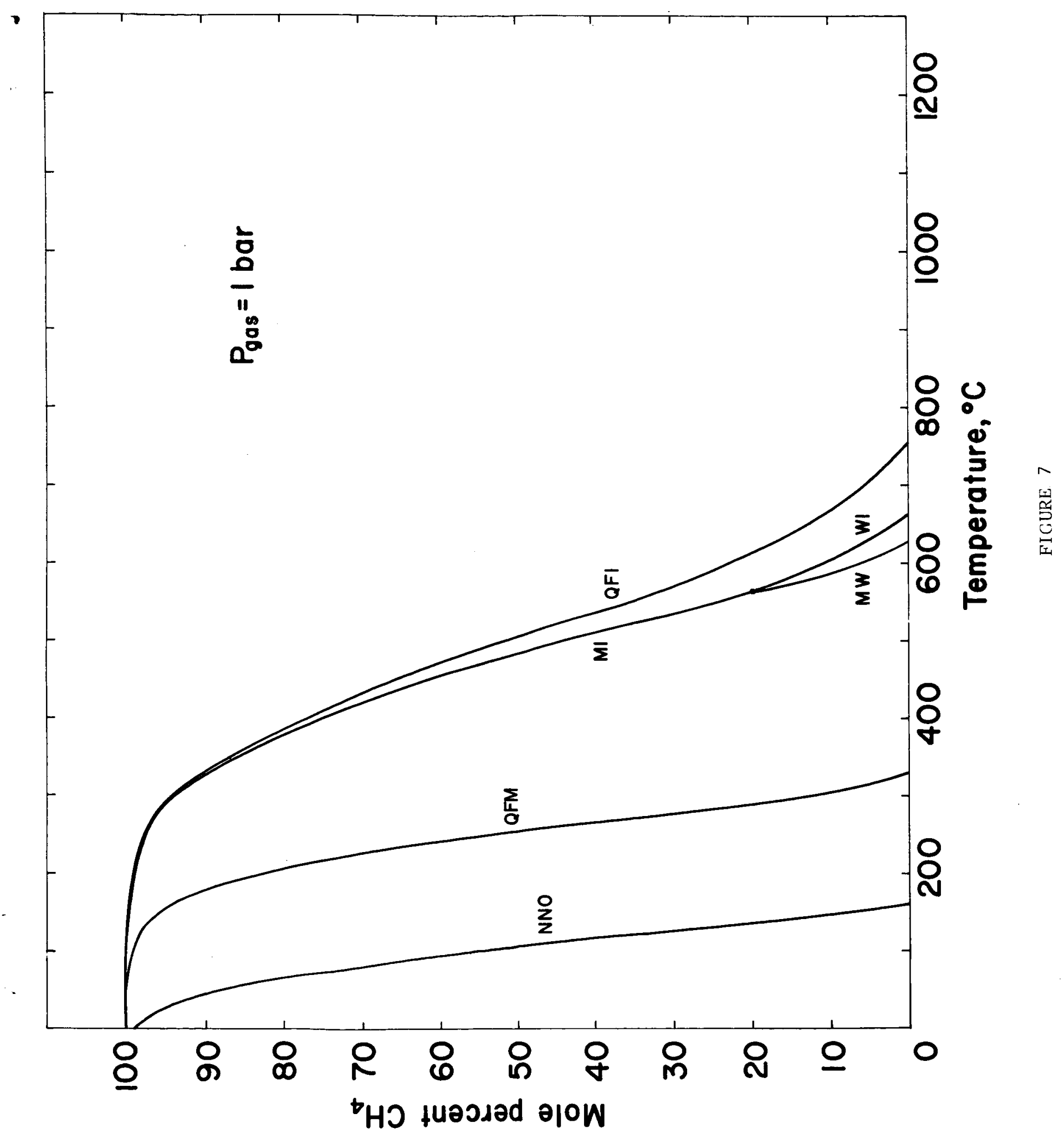




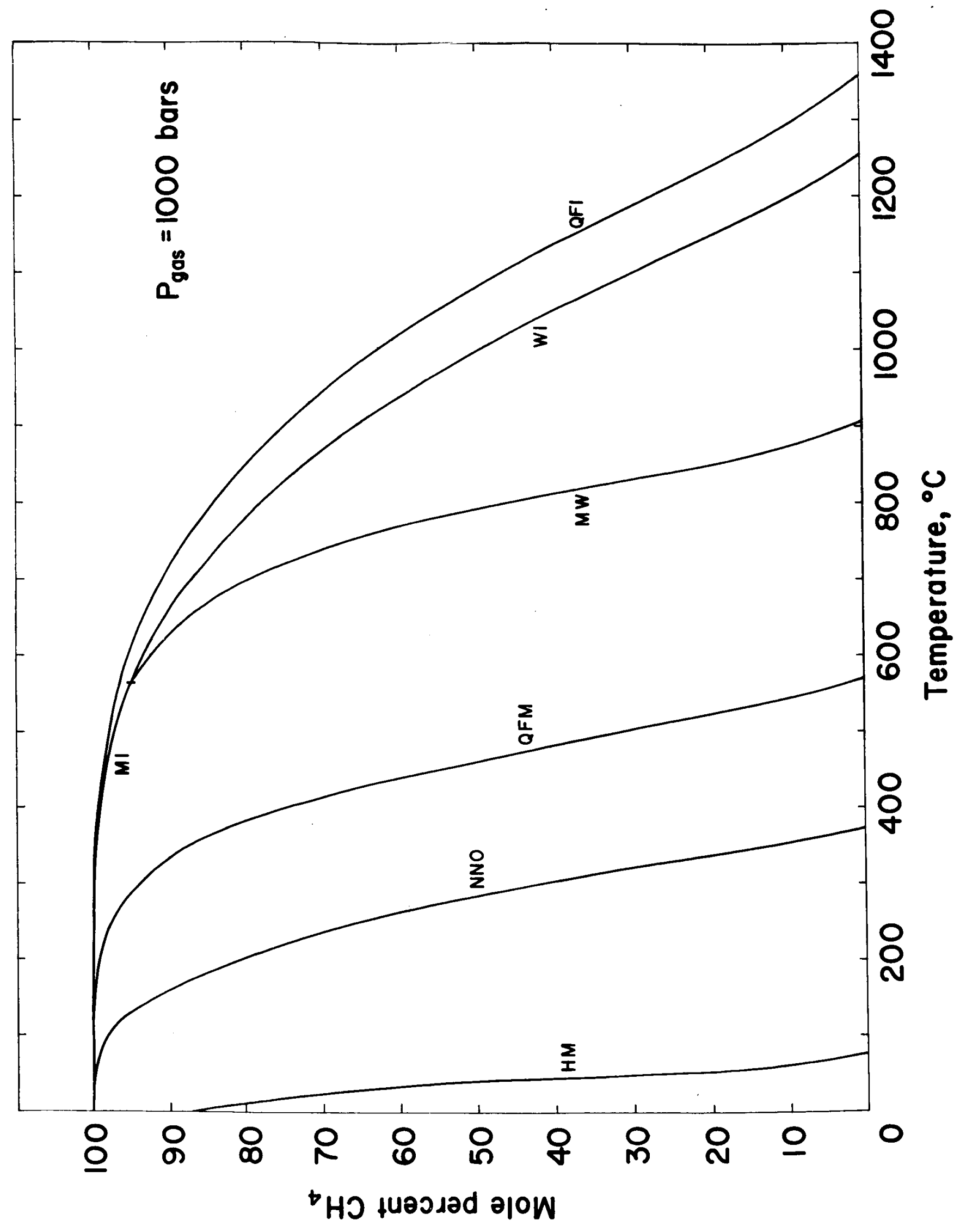


FIGURE 9

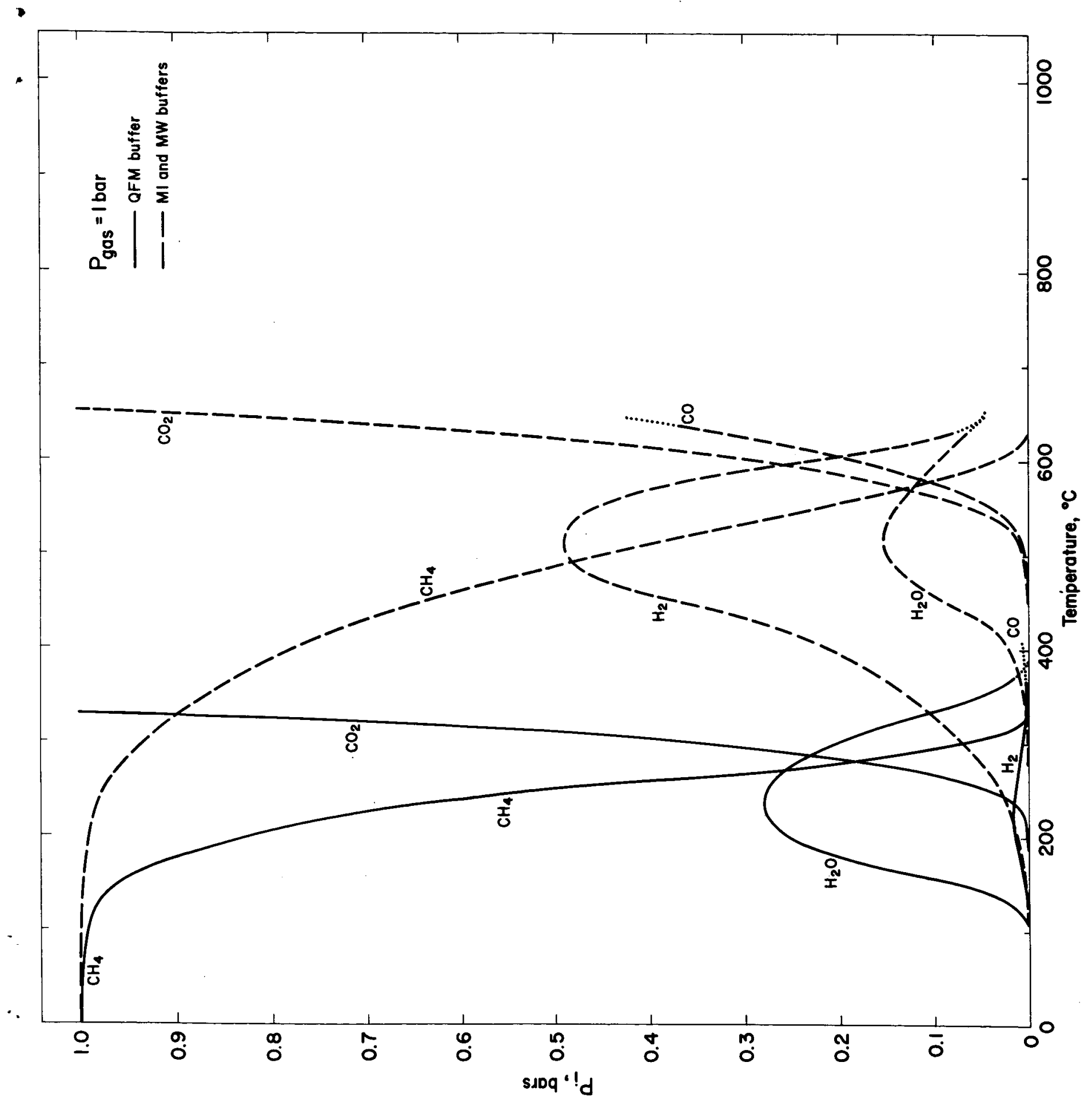


FICURE 10

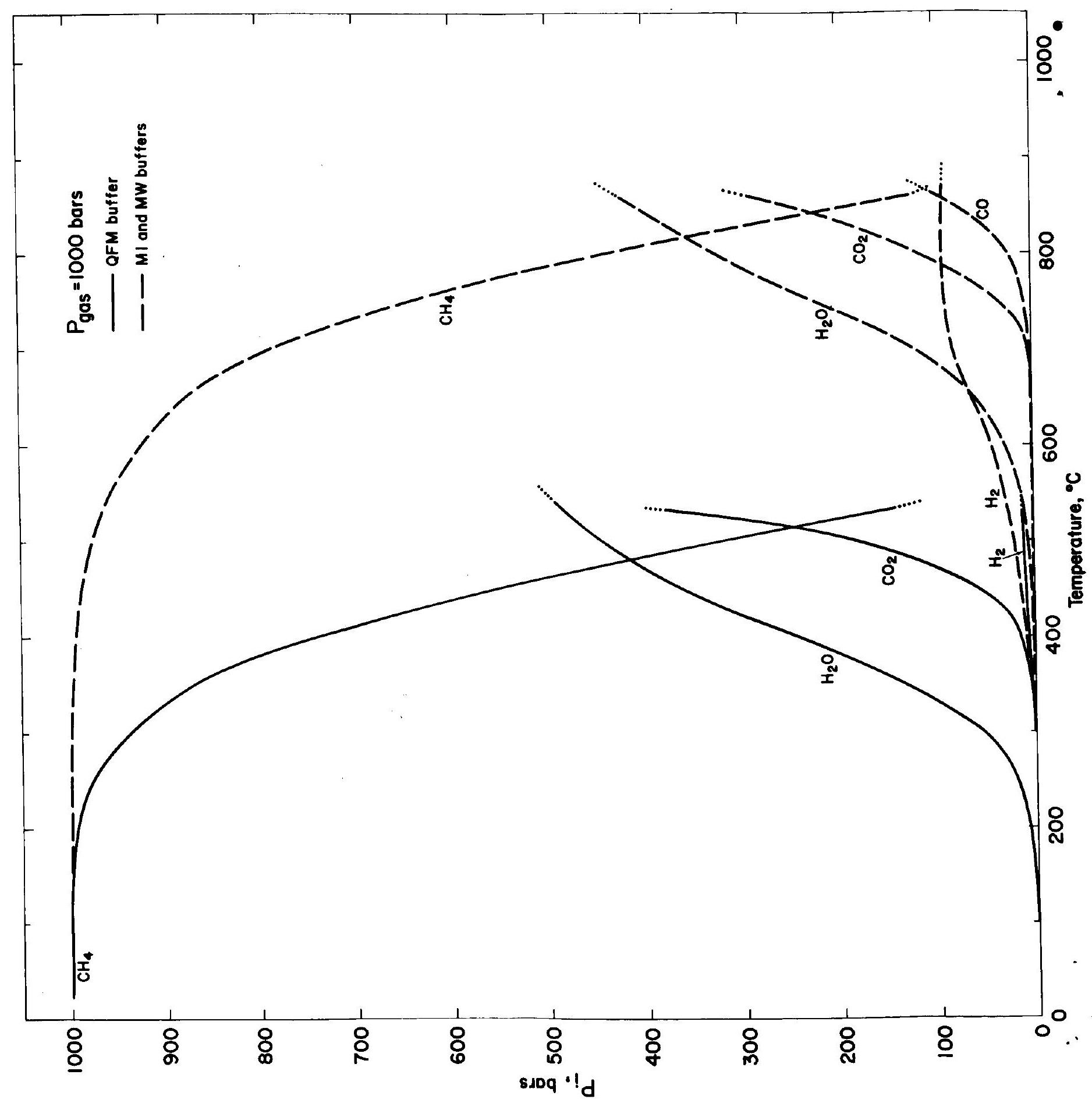




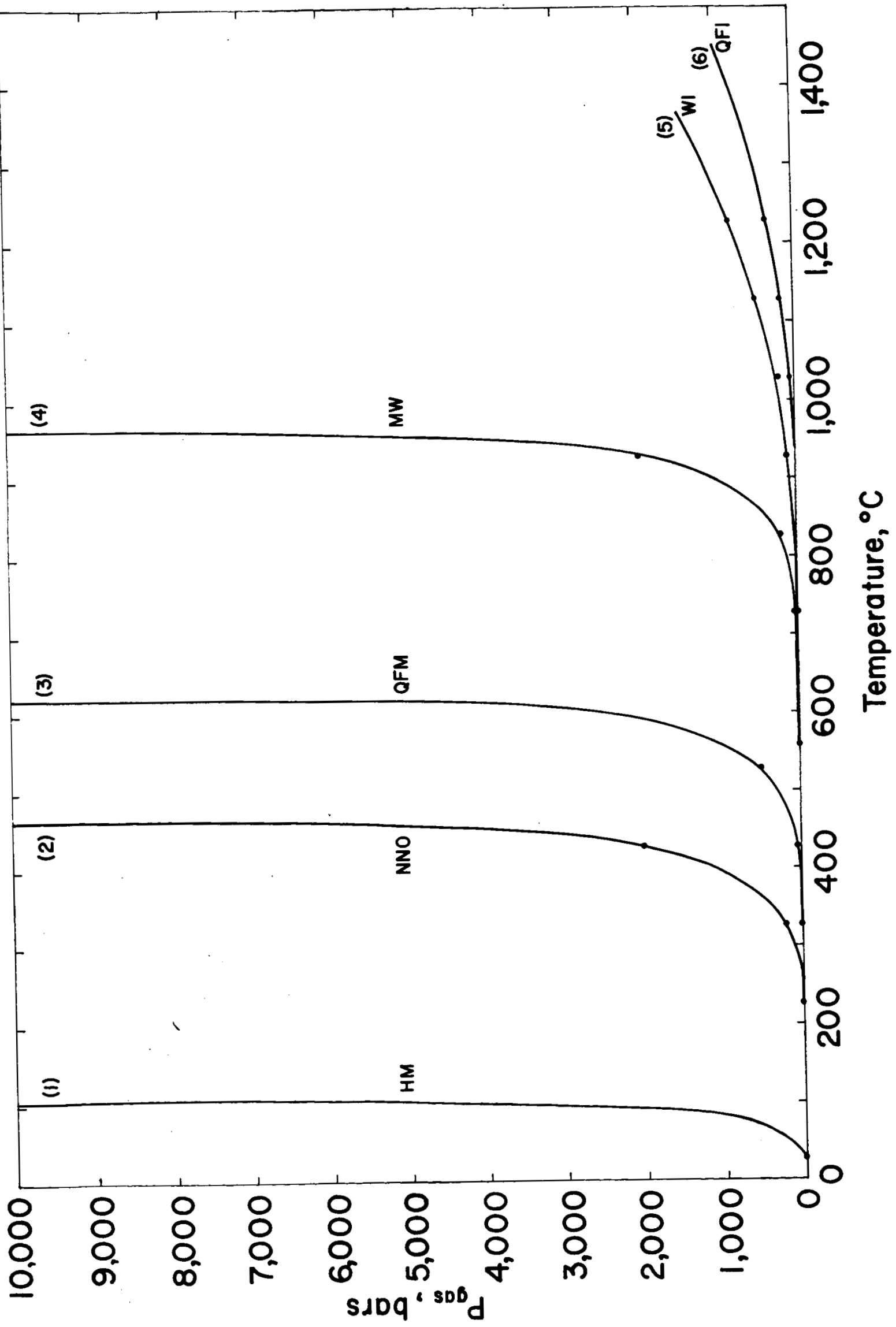


FIGURE 12

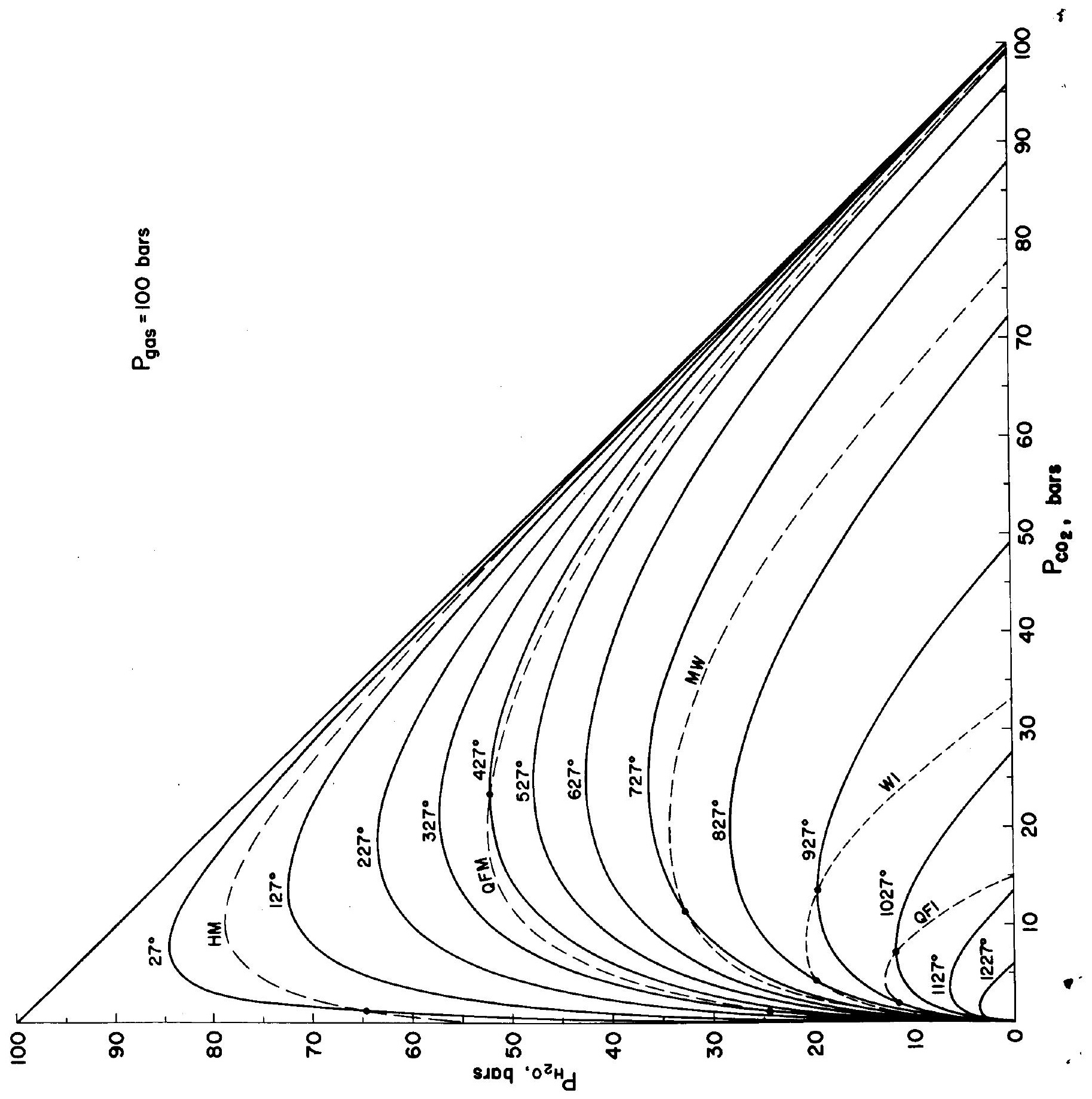


FIGURE 13

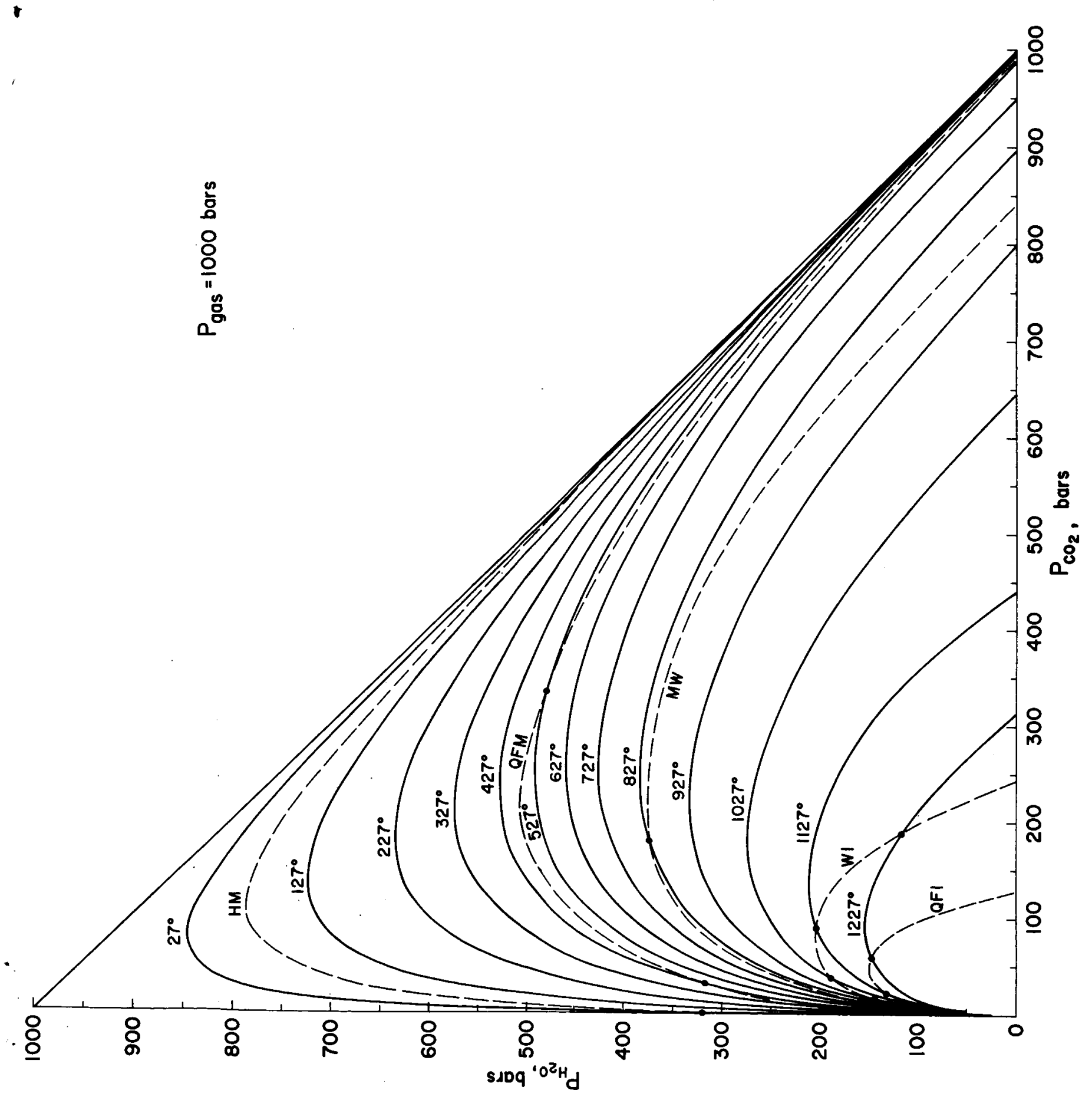




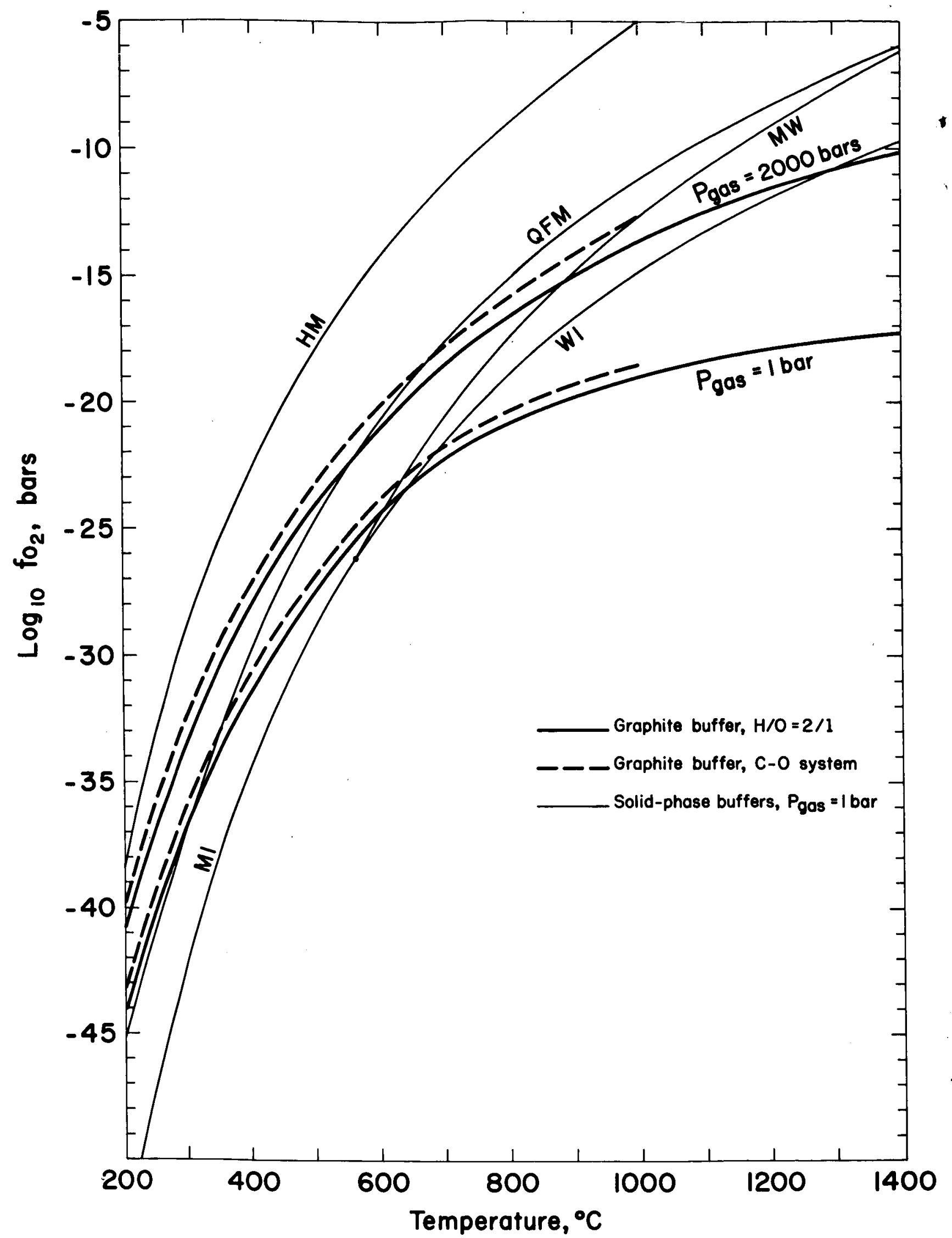




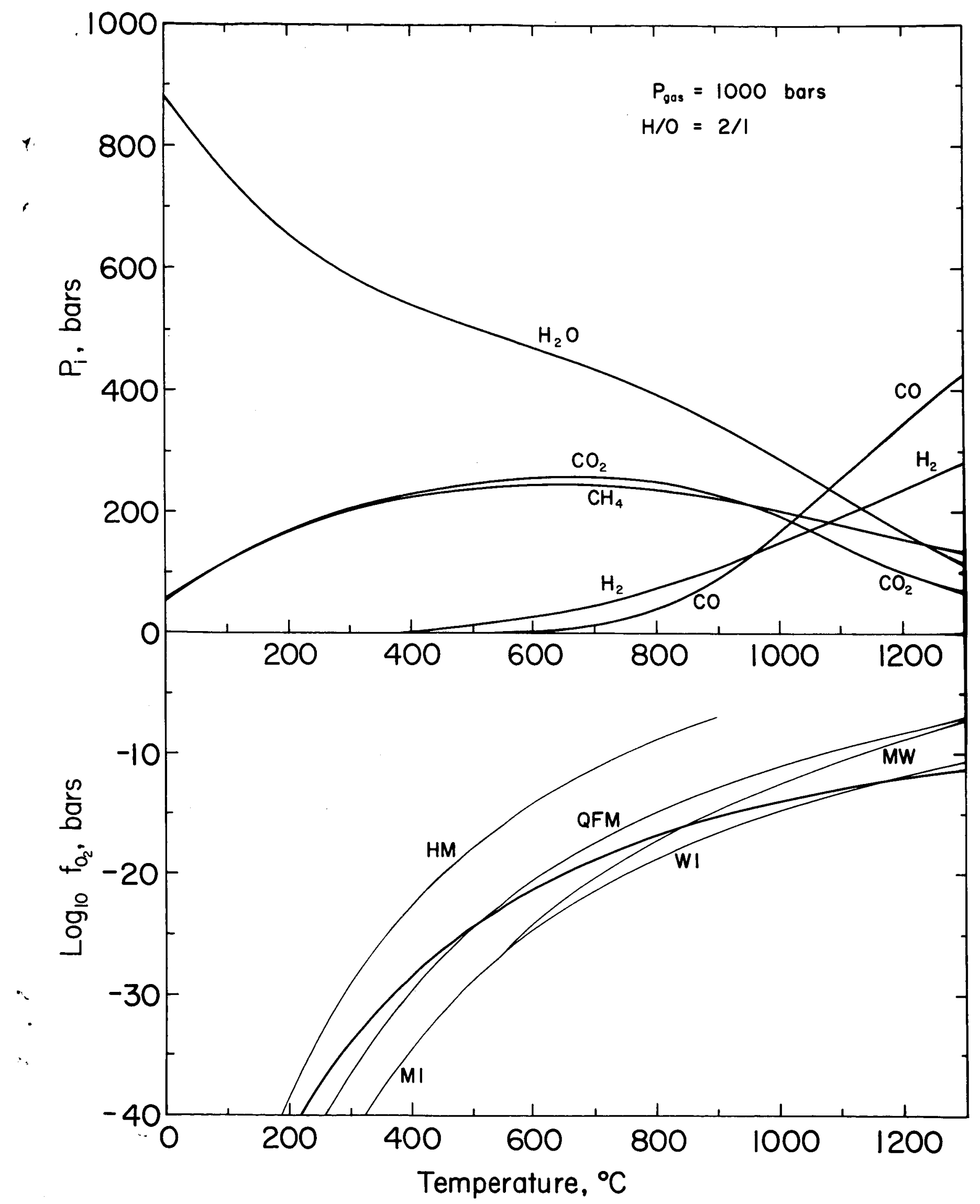

FIGURE 15 